Portland State University

PDXScholar

8-8-2001

\title{
A Dissertation on African American Male Youth Violence: "Trying to Kill the Part of You that Isn't Loved"
}

Joy DeGruy Leary

Portland State University

Follow this and additional works at: https://pdxscholar.library.pdx.edu/open_access_etds

Part of the Civic and Community Engagement Commons, Race and Ethnicity Commons, and the Social Work Commons

Let us know how access to this document benefits you.

\section{Recommended Citation}

Leary, Joy DeGruy, "A Dissertation on African American Male Youth Violence: "Trying to Kill the Part of You that Isn't Loved"'" (2001). Dissertations and Theses. Paper 3924.

https://doi.org/10.15760/etd.5808

This Dissertation is brought to you for free and open access. It has been accepted for inclusion in Dissertations and Theses by an authorized administrator of PDXScholar. Please contact us if we can make this document more accessible: pdxscholar@pdx.edu. 


\section{A DISSERTATION ON AFRICAN AMERICAN MALE YOUTH VIOLENCE:}

"TRYING TO KILL THE PART OF YOU THAT ISN'T LOVED"

by

JOY DEGRUY LEARY

A dissertation submitted in partial fulfillment of the requirements for the degree of

DOCTOR OF PHILOSOPHY

in

SOCIAL WORK AND SOCIAL RESEARCH

Portland State University

$\$ 2001$ 


\section{DISSERTATION APPROVAL}

The abstract and dissertation of Joy DeGruy Leary for the Doctor of Philosophy in

Social Work and Social Research were presented on August 8, 2001, and accepted by the dissertation committee and the doctoral program.

COMMITTEE APPROVALS:

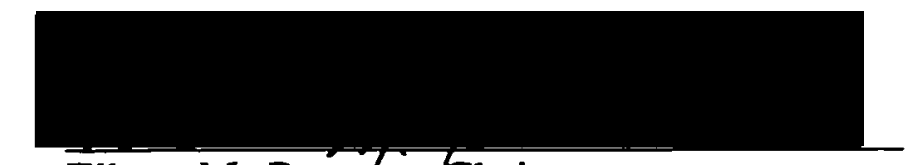

Eileen M. Brenuan, Chair
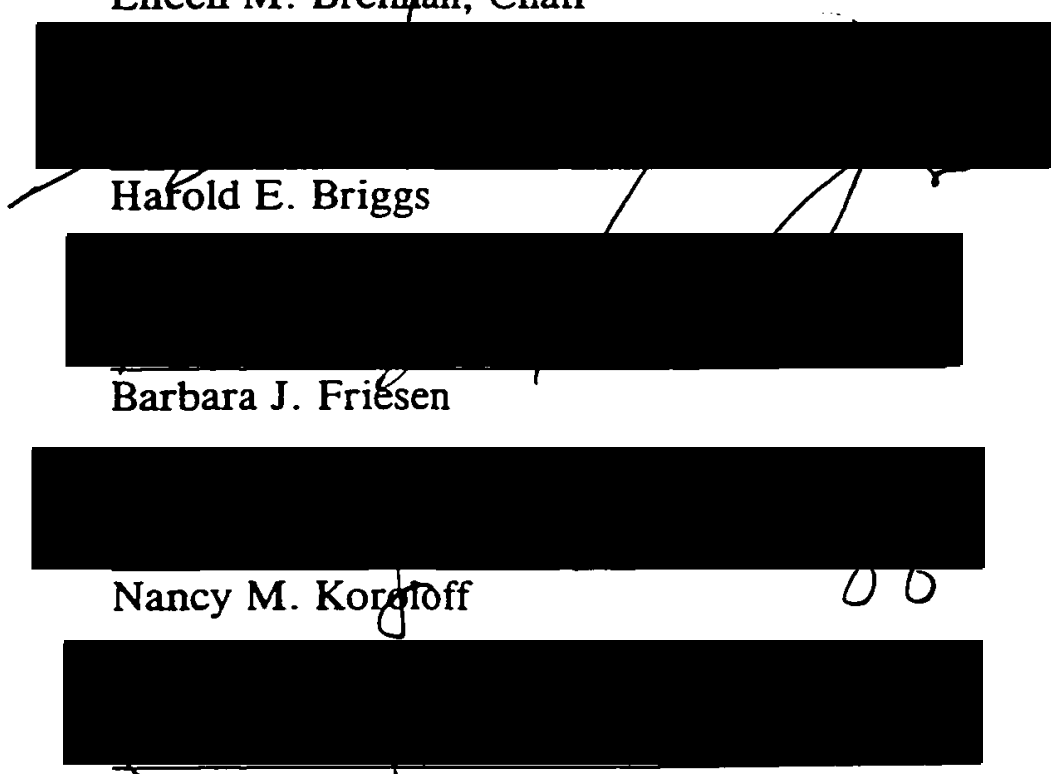

Dărell M. Millner

Representative of the Office of Graduate Studies

DOCTORAL PROGRAM APPROVAL:

James H. Ward, Dean

Graduate School of Social Work 


\begin{abstract}
An abstract of the dissertation of Joy DeGruy Leary for the Doctor of Philosophy in Social Work and Social Research presented August 8, 2001.
\end{abstract}

Title: A Dissertation on African American Male Youth Violence: "Trying to Kill the Part of You that Isn't Loved"

This dissertation is based on Sociocultural Theory, Social Learning Theory and Trauma Theory, as well as a new theoretical framework (Post Traumatic Slave Syndrome) which takes into account multigenerational trauma. Five research questions involving independent variables believed to predict violent behavior in African American male youth were investigated. The first three questions addressed stressors experienced by African Americans: violence witnessing, violence victimization, and daily urban hassles. The fourth and fifth questions concerned the sociocultural characteristics of racial socialization and prosocial attitudes toward respect. Participants were 200 African American male youth residing in inner Northeast Portland, Oregon who were recruited from four organizations: The Portland House of Umoja residential facility, McLaren Youth Correctional Facility, Donald E. Long Youth Correctional Facility and the Bridge Builders Gentlemen's Rites of Passage Program. The study included two groups of 
African American male youth ages 14 to 18,100 of whom were incarcerated and 100 of whom were non-incarcerated.

All five independent variables significantly predicted use of violence in separate regression equations. Multiple regression analyses revealed that the strongest predictor of the use of violence was victimization extent which alone accounted for $43.3 \%$ of the total variance in use of violence. In the second step of the regression, witnessing was added to the equation which increased the explained variance to $49.2 \%$. The third and final step added prosocial attitudes toward respect to the regression accounting for a total of $51.2 \%$ of the variance of the extent of the use of violence. Variables excluded from the final regression equation were racial socialization and urban hassles which failed to significantly increase the prediction of the criterion variable of extent of use of violence. The data provide evidence that trauma characteristics of absent mothers, witnessing violence, experiencing violence, and feeling disrespected by others are key factors that can provide practitioners a better lens to use in assessment and treatment planning than the current response of punishment and incarceration for displays of violent behavior. 


\section{DEDICATION}

This dissertation is dedicated to the memory of my parents, Oscar and Nellie DeGruy, who provided me with the inherited characteristics that have enabled me to realize my potential and whose love and toil helped to mold and shape the person that I have become. This work is the "fruit" of their labor. 


\section{ACKNOWLEDGMENTS}

I wish to acknowledge the Baha'i Faith as the source of my spiritual strength and personal growth, particularly the Local Spiritual Assembly and Baha'i Community for their unconditional love and support.

I graciously honor my husband Ellis Ray Leary, my champion and my hero who taught me courage and challenged me to pursue my dreams and without whose love I could have never embarked upon this journey. To my children who patiently endured my absence during countless hours at the computer and the library, I give my thanks. I couldn't have done it without their understanding and love.

I am eternally grateful to my big sister Iris, who vigilantly monitored my progress and whose insights enhanced and refined this dissertation; I still want to be like you, when I group up. To my brother Oscar, for seeing my potential in childhood and cultivating my creative and spiritual gifts, I express my gratitude. It was the experiences of growing up with my family, their nurturing, guidance and struggles that have largely motivated this work.

I humbly give tribute to Ollie J. Cross (Mom), who is the embodiment of a "saint"-someone who chooses to act decently in an indecent world. In loving memory of my grandmother Ophelia and my aunt Irene, I have pursued this work. 
Thank you for being the strong women that you were and for telling me that I was "smart."

I give special thanks to the Portland House of Umoja residential facility, McLaren Youth Correctional Facility, Donald E. Long Youth Correctional Facility, and the Bridge Builders Gentlemen's Rites of Passage Programs for allowing me to conduct my research in your facilities. To Malik Yusef, for being a catalyst that renewed my desire to serve African American youth, I thank you. To the 200 African American young men whom I had the great pleasure of meeting, thank you for your willingness to share your experiences with me.

To my staunch and loyal classmates and to my comrades, Deborah Towner, Pati Zimmerman, Dr. Jay Klusky, Verlea Briggs, Faith Holmes, Dennis Stafford, Maxcia Lizaraga, Dr. Maria Keller, Jayotta Feimoefiafi, and Joy Honodel, thank you for having my back in the trenches and for being my friends. To Michael Pullman, thank you for your selfless assistance with my data analysis and your extraordinary kindness and thoughtful manner. My profound thanks to Linda Grimes for patiently inputting all of my data, and to Pati Sluys for carefully typing this dissertation.

It is with extreme appreciation that I acknowledge and honor Dean James H. Ward and my dissertation committee for their loyalty and guidance. To Dr. Eileen Brennan, the chairperson of my dissertation, my teacher, advisor, mentor, and friend; Dr. Harold Briggs, who helped refine my raw writing skills and build my confidence as a student; instructor and scholar, Dr. Nancy Koroloff, who 
overlooked my weaknesses and encouraged me when I doubted myself; Dr.

Barbara Friesen, for sacrificing her time and work to join my committee at a moment's notice and for her commitment to excellence; and Dr. Darrell Millner, whose deep knowledge of African American history and cultural insights set me on this research path over a decade ago, I give my thanks. To Dr. Carl Bell, thank you for your patience and stern but compassionate advice. To Dr. Ethel Simon McWilliams and Dr. Kay Davis, thank you for opening the doors and creating a way for me. Finally, I would like to acknowledge Dr. Edwin J. Nichols, whose wise tutelage carried and sustained me through my personal and professional achievements and challenges. It is my sincerest hope that I shall one day obtain the privilege of making you all proud. 
TABLE OF CONTENTS

PAGE

ACKNOWLEDGMENTS $\ldots \ldots \ldots \ldots \ldots \ldots \ldots \ldots$ ii

LIST OF TABLES $\ldots \ldots \ldots \ldots \ldots \ldots \ldots \ldots \ldots \ldots$ viii

LIST OF FIGURES $\ldots \ldots \ldots \ldots \ldots \ldots \ldots \ldots \ldots \ldots \ldots \ldots \ldots \ldots \ldots$

\section{CHAPTER}

I LITERATURE REVIEW $\ldots \ldots \ldots \ldots \ldots \ldots \ldots$

Definitions and Scope of the Problem Under Study . . . . . 1

Incidence and Prevalence of African American

Male Youth Violence . . . . . . . . . . . . . 5

African American Male Youth Violence $\ldots \ldots \ldots . .99$

Explanatory Theories . . . . . . . . . . 15

Social Learning Theory

Psychodynamic Theory

Sociocultural Theoretical Perspective: Nichols' Model

The Trauma Response: African American Males

Post Traumatic Slave Syndrome (PTSS): A New

Theoretical Formulation

II RESEARCH QUESTIONS AND HYPOTHESES $\ldots \ldots \ldots . \ldots 46$

Research Question One ... . . . . . . . . 47

Research Question Two . . . . . . . . . . . . . . . 49

Research Question Three . . . . . . . . . . 50 
Research Question Four ............... 51

Research Question Five ............... 53

Summary Diagram ..................... 55

III RESEARCH DESIGN AND METHODOLOGY . . . . . . . 57

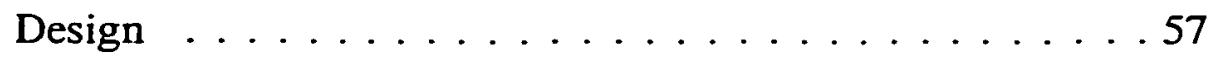

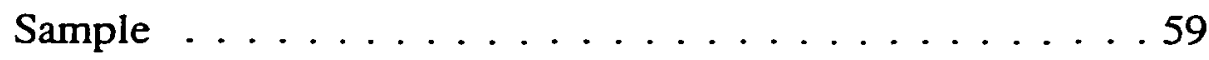

Procedures .......................... 60

Data Collection: Incarcerated Youth

Data Collection: Non-Incarcerated Youth

Data Procedures

Measurements

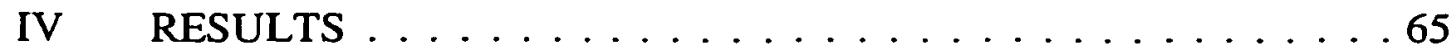

Participant Characteristics ................ 65

Hypothesis Testing . . . . . . . . . . 67

Hypothesis 1: Violence Witnessing

Hypothesis 2: Violence Victimization

Hypothesis 3: Daily Urban Hassles

Hypothesis 4: Racial Socialization

Hypothesis 5: Prosocial Attitudes Toward Respect

Additional Quantitative Analysis . . . . . . . . 87

Qualitative Data Analysis .............. 92

Past Disrespect

General Disrespect

Summary of Qualitative Results . . . . . . . . . 97 
V DISCUSSION AND CONCLUSION ............ 99

Violence, Stress, and Sociocultural Factors ........ 101

Future Research . . . . . . . . . . . . . 103

Implications for Practice $\ldots \ldots \ldots . \ldots 106$

Policy Implications $\ldots \ldots \ldots 107$

Unexpected Findings . . . . . . . . . . . . 109

Limitations of the Study ............... 111

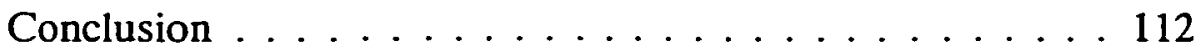

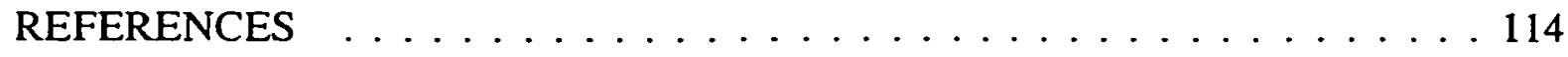

APPENDICES

A PARTICIPANT DEMOGRAPHICS ............ 120

B USE OF VIOLENCE SCALE ................ 123

C SURVEY OF EXPOSURE TO COMMUNITY VIOLENCE . . 125

D URBAN HASSLES SCALE . . . . . . . . . . . 128

E SCALE OF RACIAL SOCIALIZATION-ADOLESCENT

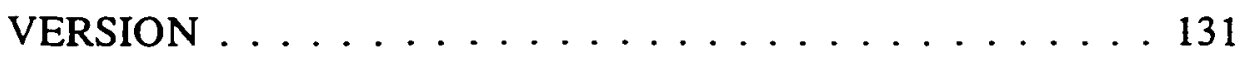

F AFRICAN AMERICAN RESPECT SCALE-MALE ADOLESCENT VERSION ............... 136

G AFRICAN AMERICAN RESPECT SCALE-OPEN-ENDED

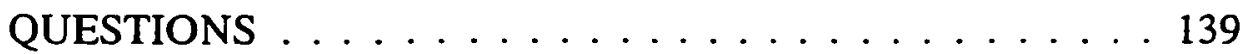




\section{LIST OF TABLES}

TABLE

PAGE

1. The Axiological Model of Inquiry ............... 35

2. Instruments Used in African American Youth Survey about Beliefs and Experiences . . . . . . . . . . . . . 64

3. Demographic Characteristics of Non-Incarcerated (NI) and Incarcerated (IY) African American Male Youth . . . . . . 66

4. Numbers of African American Youth Experiencing Individual Violence Witnessing Extent Items ... . . . . . . . . . 69

5. Individual Item $t$-tests of Violence Witnessing Intensity . . . . 70

6. Numbers of African American Youth Reporting the Use of Particular Types of Violence Through the Violence Use Scale (Extent Calculation) . . . . . . . . . . . . . 72

7. Individual Item $t$-tests of Violence Use Intensity . . . . . . . . 73

8. Regression Equation Predicting Extent of the Use of Violence from Extent of Witnessing of Violence . . . . . . . . . . 74

9. Regression Equation Predicting Intensity of the Use of Violence from Intensity of Witnessing of Violence . . . . . . 74

10. Numbers of African American Youth Experiencing Individual Violence Victimization Extent Items . . . . . . . . . . . 76

11. Victimization Extent Item \#11 - "Do You Own a Gun?" . . . . 78

12. Victimization Extent Item \#12 - "Is There a Gun in Your Household?" ................... . . . . . . . . .

13. Individual Item $t$-tests of Victimization Intensity . . . . . . . 79 
14. Regression Equation Predicting Extent of the Use of Violence from Extent of Violence Victimization . . . . . . . . . . . 80

15. Regression Equation Predicting Intensity of the Use of Violence from Intensity of Violence Victimization . . . . . 80

16. Regression Equation Predicting Extent of the Use of Violence from Urban Hassles Score . . . . . . . . . . . . . . . 82

17. Regression Equation Predicting Intensity of the Use of Violence from Urban Hassles Score ... . . . . . . . 82

18. Regression Equation Predicting Extent of the Use of Violence from Racial Socialization Scale Score ... . . . . . . . . . 84

19. Regression Equation Predicting Intensity of the Use of Violence from Racial Socialization Score . . . . . . . . . . 84

20. African American Respect Scale-Male Adolescent Version .. 85

21. Regression Equation Predicting Extent of the Use of Violence from the African American Prosocial Respect Scale . . . . . 86

22. Regression Equation Predicting Intensity of the Use of Violence from the African American Prosocial Respect Scale . 87

23. Bivariate Correlations of Criterion and Predictor VariablesExtent Calculation .................. 88

24. Bivariate Correlations of Criterion and Predictor VariablesIntensity Calculation . . . . . . . . . . . . . . 89

25. Stepwise Linear Regression Predicting the Extent of the Use of Violence for African American Male Youth . . . . . . . 91

26. Stepwise Linear Regression Predicting the Intensity of the Use of Violence for African American Male Youth . . . . . . . 92 


\section{LIST OF FIGURES}

FIGURE

PAGE

1. Summary Diagram of Predictors of African American Male Youth Use of Violence . . . . . . . . . . . . . 56 


\section{CHAPTER I}

\section{LITERATURE REVIEW}

\section{Definitions and Scope of the Problem \\ Under Study}

The origins of violence among African Americans are linked to their experience of American chattel slavery. While the existence of slavery in any society has proven to be a destructive and tragic experience for those who suffered at the hands of their captors, the impact of American chattel slavery on Africans was eminently more devastating. Unlike other societies where slavery existed, the American slavery experience was exclusively based on the notion of racial inferiority. According to Morris (1996) Africans were considered to be "presumed" or "natural slaves" based on their skin color. They were also referred to as "thinking property" and inherently "rightless persons." The institution of slavery was intrinsically linked with violence, since through the primary instrumentation of violence, aggression, and dehumanization the institution of slavery was enacted, legislated, and perpetuated by European Americans.

The direct relationship between the slave experience of African Americans and the current major social problem of African American male youth violence is difficult to empirically substantiate, given the passage of time and the practical 
issues that arise. Yet we know from research conducted on other groups that experienced oppression and trauma (Danieli, 1998) that survivor syndromes exist and are pervasive in the human development of second and third generation offspring. The characteristics of the survivor syndrome include: stress, selfdoubt, problems with aggression, and a number of psychological and interpersonal relationship problems with family members and others.

It stands to reason that the African American experience carries with it a host of stressors that are compounded when the issue of poverty is added. The "American Dream," historically promised economic prosperity to anyone who simply worked hard; however, slavery relegated Africans to an inferior status and barred this group from ever having access to the dream. The dismantling of slavery suggested that African Americans were now allowed the opportunity to achieve the "American Dream," yet Jim Crow laws enacted a system of discrimination against African Americans eliminating access to jobs, housing, education, and other survival needs (Long, 1985). Jim Crow laws were enforced from the 1800s until 1954 when the United States Supreme Court ruled them illegal. This was followed by policies enacted to promote integration which accelerated in the 1960s. The practice of integration was designed to correct past injustices by allowing for equal opportunity for all Americans regardless of race. When blacks began to move into previously exclusive white communities and neighborhoods, whites began moving out. This is frequently referred to as "white flight," and with the flight went many financial resources. During segregation, 
blacks were able to create and sustain stable businesses largely due to their having a guaranteed body of customers. They started their own newspapers, savings and loans, funeral homes, insurance companies, and beauty and cosmetic businesses that served black clientele. With integration, what happened to this prosperity? Integration was a good idea that was never sincerely embraced by the larger society and produced an even wider economic gulf that has continued into the present day. Given the stressors associated with perpetual marginalization, the widening economic disparities between African Americans and European Americans, and the lack of access to overcoming the differential opportunity structures, the rise of African American male violence may be a symptom or side effect of deprivation, social oppression and the remaining influence of slavery.

This dissertation examines the relationship between current and historical stressors unique to economically disadvantaged African American male youth by investigating issues of respect, racial socialization, and the presence of violence among two groups: incarcerated violent African American male youth, and nonincarcerated non-violent African American male youth.

The issue of respect has been an important theme amongst African American males, particularly given the historical disrespect they have experienced from European Americans beginning with slavery and continuing to the present day. Racial socialization of African American male youth by their parents or family about the existence of racism has also had historical roots linking back to the survival of blacks during and after the advent of slavery. The ubiquitous 
presence of racism in the current society has made it necessary to continue looking at behavioral reactions of black male youth with respect to these two factors.

Perceived or real disrespect, coupled with little or no racial socialization, may lead to the use of violence by black male youth. The study seeks to determine whether the key study variables of levels of issues of respect and racial socialization are related to their use of violence. The research is based on the premise that reliance of the youth on violence and their association with violent subcultures are examples of adaptive and protective mechanisms. These mechanisms reflect social, psychological, behavioral, and emotional reactions that comprise a set of unworkable responses by black youth coping with the realities, consequences, and broad implications of social oppression. This system cannot be explained by any single theoretical model alone, but is best understood by combining traditional and contemporary theories of human behavior into one comprehensive explanatory framework, and revealing their interrelationships.

Mattaini, Twyman, Chin, and Lee (1996) defined violent behaviors among youth as having multiple motivators described as "multiple response classes." The researchers stated, "the topography of violent acts varies tremendously (e.g., threats, physical attack, the use of weapons, state-sponsored terrorism)" (p. 79). Youth violence may be a function of a learned response to a traumatic event, or social and economic deprivation, or it may be a means to achieve recognition, acceptance, or respect. According to Mattaini, Twyman, Chin, and Lee, "the functions of violent behavior also vary widely, from obtaining desirable tangible 
items, to gaining social approval, to obtaining relief from unpleasant conditions" (p. 79). They suggested that effective treatment approaches are not likely to exist given "the lack of a coherent theoretical framework for understanding violence [and call for] testing approaches derived from theories with strong empirical basis of support" (p. 79).

To further support the need for more research in this area Mattaini, Twyman, Chin, and Lee (1996) sounded a call to action citing the American Psychological Association standard as a basis for judging the merits and relevance of any attempt to establish effective interventions with violent youth:

Effective intervention programs share two primary characteristics:

(a) they draw on the understanding of developmental and sociocultural risk factors leading to antisocial behavior; and (b) they use theory-based intervention strategies with known efficacy in changing behavior, tested program designs, and validated, objective measurement techniques to access behavior. (p. 79)

The lack of culturally responsive theoretical explanations and approaches to the effective treatment of youth violence has provided opportunities for the development of alternative sociocultural explanations for the numbers of youth, in particular, African American male youth, who commit and are the victims of violent acts such as: armed assault, gang fights, school brawls, and suicide.

\section{Incidence and Prevalence of African American Male Youth Violence}

Homicide is a leading cause of death for black males between the ages of 15 and 34 , and black males and females have a greater lifetime risk of dying by 
homicide than whites (Oliver, 1994). Bell (1997) laid out the gravity of this condition best by identifying homicide and suicide as major causes of death for American youth, exceeding the number of deaths due to accidents and infectious diseases. Epidemiological statistics reported by Mauer and Huling (1995) state: "A total of 23,305 murders occurred in the United States in 1994; 10,191 of the victims were white and an alarming 11,221 of the victims were black, most of whom were males between the ages of 20 and $24 "$ (p. 16). In addition to Bell's observations about victims of violence, other noted scholars have characterized the social problem of African American male youth violence as a pervasive problem, including issues of violence or harm against self such as: substance abuse and suicide. McMurray (1990) indicated:

Self-destructive behavior, as evidenced by high rates of substance abuse and suicide and pervasive acts of homicide and crime among young black men is disproportionate to other racial groups. Many others surmise that the destruction of the black male is the biggest problem facing the black family today. (p. 205)

Mauer and Huling (1995) stated the following:

When we look at violent crime, we find that African American males are identified as the perpetrators and are arrested in numbers disproportionate to their make up in the overall population. The proportion of overall violent crime attributed to African Americans has not changed appreciably over time ... What has changed in recent years is the age composition of those males engaged in violent crime, particularly with a substantial and disturbing increase in the murder rate of young black men. (p. 14)

Thus, African American men are at the forefront of the crisis of violence.

In some areas of the country, it is now more likely for an African American male 
between his 15 th and 25 th birthday to die from homicide than it was for a U.S. soldier to be killed on a tour of duty in Vietnam (Froelhke, 1991). Additionally, there is a great likelihood that those perpetrating the homicides are young African American males.

Schiraldi, Kuyper, and Hewitt (1996) reported the following:

In 1990, the Center for Juvenile and Criminal Justice conducted an analysis of young African American men enmeshed in California's criminal justice system. The research was undertaken as a follow-up to a study by the Washington-based Sentencing Project which showed that nearly one in four young African American men in the United States were in prison or jail, on probation or parole. . . . This year (1995) the Sentencing Project conducted a five year follow-up to their original study and found that, nationally one in three young African American men are now serving some form of sentence. (p. 1)

Reiss and Roth (1993), reviewing existing studies of homicide victimization and class, found that among low-income populations, blacks had much higher rates of homicide victimization than whites, but that between blacks and whites in higher income groups, there was essentially no difference. The researchers suggested that the more concentrated effects of inner-city poverty may contribute to a more serious breakdown of family and community support than is found in other lowincome neighborhoods (p. 14). Dwyer (1994, p. 6), testifying before Congress, recalled that the president of the Children's Defense Fund identified economic inequalities, racial intolerance, scarcity of jobs, and lack of education as root factors precipitating the destruction of the inner city. Additionally, violence within African American communities has led to family disruption as a direct result of 
incarceration which produced displacement of parents and children in every major city in the United States.

Cole (1999) identified economic disparity and systemic racial bias as a major contributor to disproportionate minority confinement. He stated that the majority of those serving time in prisons are poor. In 1992, more than $30 \%$ of black families fell below the poverty level compared to $9 \%$ of white families. While African Americans make up 12\% of the overall general population, they continue to account for half of the prison population.

If incarceration rates continue their trends, 1 in 4 young black males born today will serve time in prison during his lifetime meaning he will be convicted and sentenced to more than one year of incarceration ... The per capita incarceration rate among blacks is 7 times that of whites . . . African American males serve longer sentences, have higher arrests and conviction rates, face higher bail amounts, and are more often the victims of police use of deadly force than white citizens . . Nationally, for every one black man who graduates from college, 100 are arrested. (p. 5)

The incidence and prevalence of youth violence among African Americans includes different forms of violence such as gang violence, interpersonal violence including family violence, drug related violence, and school violence (Bell, 1997). Any researcher attempting to lay out the gravity of the social problem of violence among African Americans needs to acknowledge the relevance of multiple forms of violence and have knowledge of each of their devastating consequences. These data are necessary to design interventions to assist these youth to develop more healthy coping responses. Thus, the current chapter considers each of these types 
of violence as part of a much broader condition which is a result of social oppression that will be discussed later in another section.

When causes of a social problem are sought, generally traditional explanations come to mind. For example, for years many people thought that the increase in the overall incidence of violence suggested genetic and biological factors as possible causes, however neither genetic factors nor biological factors can account for the differences and variance in the levels of violence over time and place (Miczek, Mirsky, Carey, DeBold, \& Raine, 1994). Given the fact that the social problem of African American male youth violence is complex, efforts to ameliorate this problem require an exhaustive analysis of the factors associated with it.

\section{African American Male Youth Violence}

African American male youth violence is a social problem comprised of a number of sociological, psychological, biological and cultural dynamics. DuRant, Cadenhead, Pendergrast, Slavens, and Linden (1994) suggested that exposure to violence increases the likelihood that black youth will engage in violence. One year earlier Bell and Jenkins (1993) reported similar findings. For white youth, Harer and Steffenmeier (1992) found that income inequality was more likely to explain why white youth commit crimes than blacks. Hampton and Gelles (1994) did not find a relationship between exposure to violence and engagement in domestic violence; yet, what they did find was an association between engagement 
in domestic violence and employment status of the husband with unemployed African American men more likely to be violent toward their female partners than employed men. This finding suggests the influence of social and economic deprivation on patterns of domestic violence toward black women.

The pervasive nature of violence within this population makes it necessary to investigate how and why it manifests itself as articulated by the individuals who experience and perpetrate violence. The following account of a personal interview ("Jamal," personal communication, October 1997) with a young African American male illustrates the environmental psychosocial factors associated with African American male youth violence.

This brief glimpse into the life of a black youth illustrates how violence can become an integral part of daily life and the role that poverty, neglect, and institutional bias play in the perpetuation of this social problem.

Jamal Sharif (a pseudonym) is a 25 -year-old African American who grew up on the South side of Chicago. He lived with his mother and father and was the second of five children. Jamal learned early on (about 8 years old) that his mother disliked him; frequent beatings and verbal abuse demonstrated this. Jamal dreaded the beatings, but was far more injured by her verbal abuse. He managed to endure being vilified by his mother with the knowledge that following the beating was a momentary kindness that came when his mother said she was sorry.

Although Jamal did little and often nothing at all to provoke his mother's physical assaults, Jamal's mother used violence as a means to gain control and 
respect. This use of aggression by Jamal's mother in order to control him was consistent with a social learning theory framework (Longres, 1995). The results for Jamal were feelings of helplessness and humiliation. Additionally Jamal learned that violence was an effective means to exert power and influence. Jamal described his feelings during this time stating the following, "I felt worthless, like I wanted to roll up in a ball and die." He began to act out his emotional frustration through his involvement in gang activity where he frequently led "move outs" (gang fights). During these events Jamal described his violence toward others as an attempt to gain respect and a futile effort to "kill the part of me that was not loved."

Jamal repeatedly referred to the difficulties that he and his family members experienced financially and socially as being caused by the mainstream racist structure; there was a lack of recognition and understanding by the wider society of the cultural values of African Americans and of the adverse conditions under which they lived. He suggested that the schools as well as corporate institutions served to destroy black culture by providing inferior education to black children like himself, and forcing black men to become invisible in European American dominated corporations.

Much work has been done to understand young African American men like Jamal. Violence and its effects have dominated the discussion. Various theoretical approaches have been proposed to explain such behavior. Youth have been interviewed with the goal of understanding what has led them to behave as they 
did. DuRant et al. (1994), in their research about the use of violence among urban black adolescents, proposed a cultural transmission theory which suggests that violence, along with crime and juvenile delinquency, are learned within interactions with family, peers and significant others. The result of this work is that we have many theories to explain behaviors like those of Jamal's, and while we do not understand all there is to know about behavior and its determinants, we do understand a fair amount. Mostly we understand behavior that does not work, why it does not work and how that behavior likely originated. To the degree these understandings have led to workable methods for addressing youth violence they have been useful. Many researchers and practitioners like Fitzpatrick and Boldizar (1993) and Bell (1997) continue to advance our knowledge by studying these issues.

What social factors are in play when a person behaves reasonably and peaceably? Are there environmental factors which contribute to such behavior? It goes without saying that practitioners working with African American youth want them to be healthy. All youth who behave inappropriately at one time will behave appropriately at another. What makes the difference? Are there approaches that practitioners can apply to assess and promote such behavior?

In this study the extent to which male youth violent offenders are affected by their attitudes toward respect or disrespect will be examined. For African American males the issue of respect includes sociological, social psychological, family of origin, cognitive and behavioral characteristics. 
In subsequent interviews with Jamal he revealed that did not feel appreciated as the person he thought he was; he did not have the approval or recognition by society, school teachers and family members, especially his own mother. Consequently, he felt disrespected and not recognized as a worthwhile, contributing individual.

Psychodynamically, Jamal was not allowed to individuate and emancipate as a creative thinker or develop prosocially as an imaginative, innovative person worthy of social resources or respect. At home he experienced rejection and humiliation and in society he was not considered significant. He doubted his thinking and was not open to learning because of the lack of teacher supports, ridicule, labeling, and not being understood either at school or at home. He looked at his situation and concluded that he could not make it in the legitimate society. He doubted that legitimate society was available to him and he developed an identity and ego support system with peers, and sought after symbols of false achievement and success. These things mean that he had attained a level of respect within his peer group. The issue of respect plays an essential role in the lives of many black youth living in urban communities across the United States. There is a strict street code associated with respect that is socially regulated and supported (Anderson, 1999).

Behaviorally, Mattaini and Thyer (1996) talked about the lifestyle of youth like Jamal within an observable and functional relationship framework incorporating the realities of social oppression, situational conditions at home, 
school, and community and the target behavior of violence and associated consequences (these typologies are explained later in the theory section). We now need to consider the behavioral characteristics that accompany the trauma of growing up poor, unsafe, unsupported, and not nurtured as a respected and honored individual. To do that would mean that practitioners would need to examine the hassles of being African American, the repeated experiences of trauma that occur at home, school and community with African Americans, and the relevance of material, economic, and personal gains as a basis for establishing self respect. In this sense, this would mean that youth will be antagonistic toward people but not because of their person; the reason for their violence toward people is to achieve resolution of physiological arousal, stress, personal gain and satisfaction, and economic and material gains. At home and at school, youth like Jamal are not encouraged to succeed or to develop positive skills. He saw his learning experience as not helpful, supportive or caring. Also, his character and value system were considered perverse by adults. He never received reinforcement or encouragement from caring and supportive adults for trying to do the right thing. Systemically in communities and neighborhoods which their friends and peers frequent, youth like Jamal will often get their advice and support from members of an underworld they respect and understand. This illicit culture provides the youth with exposure to new opportunities by belonging to a street or community-based reconstituted family. The members of this group provide each other support and encouragement as well as security and respect. 
The personal history of Jamal Sharif is reflective of the kinds of urban struggles and hassles that many African American male youth experience. The multifaceted nature of these hassles include the elements of being poor, living in unsafe neighborhood environments, and the associated violence and harassment from peers and strangers who urge the youth to buy or sell drugs or to join gangs. Finally, these youth are forced to contend with overt racial discrimination from educators, employers, law enforcement officials, and judicial professionals among others.

\section{Explanatory Theories}

\section{Social Learning Theory}

According to Longres (1995) social learning theory is useful as a framework for understanding the problem of African American male violence. In this context, male youth violence is a result of a process of imitation and vicarious adaptation to the experiences of others in the environment. Patterson's (1995) research on coercive family patterns highlights the importance of the social learning theoretical model in explicating the ways that youth that adopt aggressive behavioral repertoires are reinforced by their parents. Children learn socially appropriate as well as antisocial behavior from parents, siblings, and peers, principally based on individual cognitive processes that, in turn determine individual behavioral responses. Bandura (1969) described learning through imitation and modeling regardless of incentives or punishment (Longres, 1995). 
For this learning to occur the observer must have a basic awareness of the events which are occurring, and arousal based on his or her understanding and unique needs. In addition, the observer must be able to retain and interpret the events as they are occurring in order to reproduce or model the behavior. Perhaps the most important cognitive process is the internal or external incentive to perform the particular behavior. External motivation could include material rewards that act as reinforcement, and internal rewards may include acceptance, positive feelings of esteem, and approval from significant others (Longres, 1995).

Another way of using social learning theory to understand male youth violence involves recognizing violence among African Americans as the result of the individual's adjustment to events which may be life threatening and to which they must be attentive. The social and psychological motivations could come from a host of areas particular to the situational violence. For example, in gang situations violence is often motivated by social approval and acceptance, drug related violence is motivated by material gain, and individual and personal violence (an altercation with a friend, sibling or acquaintance or, harming oneself) involves a multitude of motivational variables such as the need for personal safety, unresolved or displaced anger, feelings of hopelessness, and depression. In order to better understand how feelings of hopelessness and active depression can lead to violence, it is necessary to understand how these characteristics often manifest themselves within African American males. 
Indeed, African American males are often diagnosed as having antisocial personality disorder or having sociopathic tendencies when they are actually experiencing depression with suicidal ideation. Some African American psychologists are calling these behaviors commonly identified as antisocial and homicidal as a form of "invited suicide" (Davis-Russel, 1990). This pattern of arranging self-defeating contingencies and behavior is consistent with ideas advanced by Mattaini and Thyer (1996).

Mattaini, Twyman, Chin, and Lee (1996) provided six different classes of violent behaviors and their associated functions: (a) power and control, (b) positive reinforcement, (c) biological, (d) conflict resolution, (e) respect, and (f) culturally defined enemy. The first class recognizes violence motivated by power and control. Mattaini, Twyman, Chin, and Lee identified this explanation as being consistent with feminist theory about the causes and functions of battering behaviors. In the instance of African American male violence, there is a contingent relationship between power and control over victims. An example of this class of violent behavior can be understood using the "new kid" as an example to illustrate the point. Youth who commit violent acts as a function of power and control experience a significant degree of deprivation; they may be living in homes or communities where violence is a typical way of communicating feelings or resolving issues, and they may be using illicit drugs or alcohol. These same youth may encounter the new kid as a person who thinks he is better than the other youth in the community. The unsuspecting or potential victim may simply walk by and 
ignore a group of them as they are standing around or he could give them a disapproving glance when they called him a name or talked about his mother. Any of these circumstances could serve as an incentive or motivating condition of disrespect to the perpetrator. The combination of the negative social and familial conditions and the experience of disrespect provide the foundation for youth to commit violence. The presence of friends combined with the consequence of avoiding disrespect in the future is a useful way of understanding violence as a function of control over one's environment.

Mattaini, Twyman, Chin, and Lee (1996) suggested a second class of violent behavior which occurs as a function of positive reinforcement. In this context, African American male violence may occur when the perpetrator is experiencing social and material deprivation. Having no money, no popular clothes, no or negative attention, together with the availability of a victim and the presence of friends or "partners," provides the motivation and the recipe for a violent act. The consequence of this behavior is that the perpetrator has obtained the money, clothes, and attention.

A third class of violent behavior that results from rage includes a biological component. In this instance, the African American male youth offender experiences the same antecedents as stated in class two explanation but also possesses a type of rage which serves as the motivating condition. Violence perpetrated as a result of rage is then followed by a reduction in the physiological arousal condition. 
A fourth class of violent behavior functions to resolve conflict. In this instance, the youngster is faced with a host of unsatisfactory events such as his "girlfriend" not acting according to code and talking to other boys. This behavior is then followed by the youngster's demand that she cease this undesirable behavior; yet, she fails to yield to the warning. This conflictual cycle is then followed by violence to gain compliance and to uphold the rules which govern the relationship. Compliance with demands and rules are then achieved following the violent act.

A fifth class of violent behavior is street violence as a means to gain respect. Bennett and Fraser (2000) explain:

Simply maintaining eye contact with an individual for "too long" may be viewed as a lack of respect, an affront that can escalate into a confrontation. In a similar vein, a snide remark that might otherwise be viewed as trivial may lead to an "honor contest" where no party backs down until someone is injured. (p. 100)

Mattaini, Twyman, Chin, and Lee (1996) described this type of violent behavior as a function of a myriad of antecedents and motivating conditions from multiple sources that collectively influence the probability of violent activity. The researchers explained this type of violence as having four different actors such as "a victim, a perpetrator, peers of the perpetrator, and a bystander" (p. 101). They next described how this type of violence occurs. Mattaini, Twyman, Chin, and Lee stated that:

Each class of actor emits, or fails to emit a particular cultural practice. Generally speaking, a cultural practice can be defined as a behavior transmitted and supported by a cultural entity.... The 
sequence starts (1) when the victim walks down the street going home from school (his motivations for doing so are unrelated to other actors in the scene). The perpetrator confronts and attacks him (2) One of the most powerful motivating factors for the attack is the respect (social reinforcement) provided by peers who are present (3). The perpetrator himself (4) may reciprocate this reinforcement. Bystanders take no action, perhaps because they have had previous experiences with violent groups of young persons on the street or because of self talk (rules). (p. 101)

A sixth class of violent behavior is the result of action taken against a culturally defined enemy. This type of violence is focused primarily on the antecedents, motivating conditions, and consequences of violence between two rival groups. In this instance, violent acts are preceded by: (a) rules which define members of group A as no good, (b) the presence of enemies, and (c) peers of group A, (d) deprivation, (e) a number of aversive stimuli such as substance use, negative attention, lack of resiliency supports, ( $f$ ) an enemy group seems to be provocative, (g) members of group A perceive the possibility of personal harm and risk, and (h) members of group B are acting disrespectful. These conditions are then met by violent actions. These actions generally are followed by biological conditions such as feelings of arousal and physical damage. What are likely to follow are desirable social consequences such as: (a) increase in respect from family and peers for hurting the enemy and (b) personal consequences such as the reduction in risk of injury and harm, not to mention the removal of the aversive condition produced by the enemy group's presence. 


\section{Psychodynamic Theory}

Based on psychodynamic theory, African American male violence could be described as a failure of the superego to inhibit socially unacceptable behavior. This may be due to a lack of gratification in earlier stages of development which caused unresolved disharmony within the individual resulting in psychological difficulties. In the case of African American males, the psychological difficulties are reflected in violence. The theory suggests that disruption in earlier phases of development, like failure to secure or satisfy basic needs, could result in maladaptive behaviors. Given the state of racial inequality and oppression currently existing in the United States, basic needs continue to be unmet for large portions of the African American population (Chestang, 1972).

According to Chestang (1972, p. 1), the "Black Experience" consists of destructive conditions brought on by racial intolerance from a hostile society which adversely impact the personality. Those conditions include: social inequity, powerlessness, and societal hypocrisy.

The impact of these variables greatly endangers the psyche of African Americans in general, but perhaps has an even greater influence on black male youth. Living in a hostile environment results in a multitude of inner conflicts reflected by the development of an "alternative conscience" (Chestang, 1972, p. 1) to guard against the discriminatory behaviors of the dominant social structure. The lack of societal consistency results in frustration, confusion and bewilderment. 
The individual attempts to cope with the injustices and hostility by attempting to buttress the self by developing a "dual reality"; on the one hand the "depreciating character," one which fulfilled the stereotypical ignorant and inferior individual (Chestang, 1972, p. 8), and the other hand the "transcendent character," that becomes resilient and transforming in the face of severe trials (p. 10).

Chestang (1972) further suggested that when individuals have to survive in a hostile environment they develop: (a) a depreciating character or (b) the transcendent character. Persons with the depreciating character express dissatisfaction with the rules to obtain goods, services and opportunities and secure their survival through illicit and socially unacceptable means to achieve immediate gratification, security and acceptance. The depreciating character will either "act out" (i.e., African American male violence) or "act in" with self-destructive behaviors such as abuse of drugs and suicide. Pinderhughes (1989) asserted that when individuals feel powerless they will find ways to "neutralize their pain with strategies that will enable them to turn that powerlessness into a sense of power" (p. 124). She stated:

Inspiring fear is another way of turning powerlessness into power. A Black psychologist made this point to a white colleague: $\mathrm{My}$ powerlessness as a Black male in the American system often leaves me with one sure way to get a sense of power--to scare you. (p. 126)

The second character option is the transcendental character which attempts to rise above acting in or out by surpassing the limitations imposed by the other characters. Chestang's theory of character development implies the existence of a 
third character, the integrative character, which adopts the hopes and dreams and behaviors of the oppressive or dominant group as their own in order to survive (Chestang, 1972).

Sociocultural Theoretical Perspective: Nichols' Model

The Nichols (1976) sociocultural theory helps practitioners understand the relationship between violent behavior and the cultural value system of African Americans, and the population of interest in this study, African American males. This value system places emphasis on the maintenance of the integrity of relationships. When this value system is compromised, the opportunity for disintegration of relationships between African American males and society is likely to occur. This leads to an increase in altercations between members of the same group and others, the need to secure role models and symbols of success regardless of the costs and expense to themselves and others, and in an effort to buttress the perceived cultural assault to the self concept, the African American male develops an alternative system of achieving respect and self worth.

Dr. Edwin J. Nichols (1976) created a model emphasizing the philosophical aspects of cultural differences. The model explores four philosophical aspects of cultural difference that drive the way individuals in a culture interact with the world: axiology, epistemology, logic, and process. The differences related to these aspects are so fundamental they lie below our everyday awareness. The 
assumptions that they generate are almost never questioned. Of the four aspects that Nichols' presents, axiology is the most pertinent for this discussion.

Axiology is the study of the nature and criteria of values, (i.e., what value a culture holds in highest regard). Nichols' (1976) axiological construct identifies and elaborates on the concepts and themes that relate to values within specific cultural groups. The axiology of a people is largely determined by their survival adaptations over time. These adaptations generate the primary value systems of the particular cultural group and become the template upon which future generations derive their understanding of how to meet their needs. Nichols asserted that once the primary "values" have been established, they endure throughout millennia. Nichols identified four major axiological constructs:

Member-Object: Characterizes the European axiology in which the highest value lies in the object or the acquisition of the object.

Member-Member: Characterizes the African, Arab and Hispanic axiologies in which the highest value lies in the relationship between people.

Member-Group: Characterizes the Asian axiology in which the highest value lies in the cohesiveness of the group.

Member-Great Spirit: Characterizes the Native American axiology in which the highest value lies in one's relationship with the Great Spirit. (p. 1)

The African axiology. According to Nichols (1976), the primary value system that dominated the African continent was Member-Member. This axiology places the highest value on the "relationship" between individuals, the relationship being the most important factor in regulating the majority of human activities 
within the culture. The member-member axiology suggests that the survival of the group is primarily dependent upon the integrity of relationships among the members of that group.

According to Asante and Asante (1985), African societies were arranged based upon kinship relationships. The extended family was an interdependent unit that provided for the care of children, the sick and the elderly. The extended family structure was part of a survival strategy, particularly for Africans whose kinship ties provided the mechanism for child-rearing and social organization. All members of the family helped to provide for the basic needs of food, clothing and shelter. Cooperation within a close-knit family insured the continued existence of the particular tribe or group. Consistent with the focus on interpersonal relationships is the responsibility and accountability of each member of the tribe for their personal actions and behaviors. Thus, the African adage, "what goes around, comes around." Asante and Asante explained:

There was an organic view that the whole order was related in a dynamic sense. Tampering with one part was believed to affect the whole. All parts had to be in rhythm and harmony with one another leading to a sense of connection for the cosmos. Time, in traditional African culture, has been viewed as a central phenomenon. The worldview has had a religious base and has emphasized an external locus of control and the need for humans to temporarily harmonize themselves with the forces of control and the forces around them. Time has been used in establishing a complexity of balanced relationships; one, time as used to establish a relationship with the Supreme Being; two, to establish a relationship of continuity between the present and past generations; three, to establish a relationship with nature and the forces of one's environment (nature); and four, to create group harmony and participation among the living. (p. 31) 
Compatible with the principle of maintaining harmony and connectedness, much of the political arrangement of African societies was decentralized showing little concern for control over territories. These "stateless societies," relied principally on consensus, custom, and traditions rather than legislative processes (Mazrui, 1986). Relying on consensus confirmed that all individuals were important in determining the movement and direction of the whole group.

The member-member axiology is governed by the principle of interconnectedness. All things in the universe are related in a dynamic balanced way with both internal and external loci of control. This axiology suggests an ontological universe of interconnected spiritual and temporal networks, with which people ideally strive to synchronize themselves. Mbiti (1970) described this universe:

.. . There are five divisions of the ontology, ranked in order of descending importance: (1) God, (2) spirits, (3) man, (4) animals and plants, (5) inanimate objects. The ontology is anthropocentric in that attention is focused upon man (humans) as the center. Humans are acutely aware of their position in relation to other forms of existence since a balance must be maintained at all times and since all modes must keep their proper place and distance from each other. Unity and interdependence are crucial since an upset in one of the categories upsets the whole order. God is believed to be the creator, the sustainer, and the ultimate controller of life; Africans thus have little difficulty reconciling $\mathrm{His}$ intervention into the affairs of humans, even though the spirits are believed to be His emissaries. Darryl Forde (1954) further describes this relationship: "God, spirits, and magical forces beyond the community are postulated in explanation of the workings of the universe, of the incidence of benefits and misfortune, and of the strains of life in society." (p. 64) 
The implication of the African axiology is that a fundamental level of "respect" exists amongst members. This respect becomes the linchpin for the sustained health and survival of the group.

Given this view of the world, each individual is viewed as an important integral part of the whole. Rather than individuals being treated as replaceable units, this view demands that we treat each individual as crucial, for altering the individual consequently alters the whole. Therefore, each person, in and of himself or herself, is seen as a cherished and vital entity. This is the foundation of the member to member axiological construct.

With the onset of the slave trade in the Americas the very fabric of Africans' lives was torn. Slavery violated the member-member axiology as familial and tribal relationships were disregarded and dissolved. Violating this axiology over generations resulted in: large groups of people feeling unapproved, unrecognized, disrespected, unsafe, conflicted, confused and with a heightened sense of shame. In Africa, self-respect was earned as a result of being a contributing, equal member of one's tribe, thus everyone had worth. As a result of slavery, individuals were remanded to a group level of inferiority where no one had worth. The question became, "How does one establish a sense of worth when all of the members of your group are deemed inferior?" During slavery, levels of African American males perceived each other as inferior as a group, and sought to establish respect by establishing superiority and inferiority within the group. Thus, respect became an issue of power. The lighter skinned slave was deemed superior 
to the dark skinned slave and thus had more power. The house slave was deemed superior to the field slave and thus had more power.

According to Morris (1996), the lighter skinned children were often fathered by white slave masters and enjoyed more privileges than darker skinned slaves as evidenced by the fact that mulatto people were sometimes allowed their freedom after a period of indenture while black slaves were bound to a lifetime of servitude. Morris explained:

By the end of the colonial period Whites clearly no longer felt comfortable with the enforced servitude of mixed-race children . . . This was because of an increasing humanitarian sensibility by the end of the eighteenth century, the collapse of the institution of indentured servitude, and a "promulatto bias" that emerged by the nineteenth century. Cobb provided an illustration of the latter in his Historical Sketch of Slavery when he discussed the lack of chastity in female slaves and the "corresponding immorality in the white males." An important cause, in his view, was that the "negress knows that the offspring of such intercourse, the mulatto, having greater intelligence, and being indeed a superior race, has a better opportunity of enjoying the privileges of domestics; in other words, is elevated by mixture of blood." (p. 24)

The preferential treatment of slaves based on skin is clearly illustrated in the intimate relationship between Thomas Jefferson and his mulatto slave, Sally Hemmings with whom he fathered a child. Ms. Hemmings was favored by Jefferson for her fair skin and flowing hair (Branscom, 1998). In sharp contrast to his sexual attraction to Hemmings, Jefferson, when referencing dark skinned slaves referred to their skin color as unattractive, animal like, and monotonous (Peterson, 1975). 
Slaves often took on the characteristics of their oppressors. Black drivers (foremen of the slaves) and overseers who were assigned the duties of monitoring and disciplining the field slaves, were often more brutal than their European counterparts because slave masters rewarded them for their cruelty. Genovese (1976) shared this glimpse:

The head driver is the most important Negro on the plantation. He is to be treated with more respect than any other Negro by both master and overseer. He is on no occasion to be treated with any indignation calculated to lose respect of the other Negroes without breaking him. He is required to maintain proper discipline at all times. To see that no Negro idles or does bad work in the field, and to punish it with discretion on the spot. The driver is not to be flogged except by the master but in emergencies that will not admit of delay. (p. 383)

Genovese (1976) described how children practiced behaviors which

reflected the realities of slave life.

Some of the games reflected the children's slave condition. Julia Blanks of Texas remembered the children's favorite game as whipping each other with switches. "You Know," she added, "after you was hit several times it didn't hurt so much." And then, there was the game of playing auction. One child would play the auctioneer and pretend to sell others to a prospective buyer. ( $\mathrm{p}$. 506)

In the absence of material possessions and social position, power is often defined based on brute strength. As a result of slavery, not only were members discouraged from developing respect for each other, they would not develop respect for themselves. 
This translates contemporarily as a lack of political, material, social and economic power which has resulted in aggression as a means of securing mutual respect within African American relationships.

The psychosocial, behavioral and relational injury resulting from protracted trauma and oppression resembles injuries of other survivors of trauma such as: Holocaust survivors and their families, Japanese American Internment survivors and their families, World War II prisoner of war survivors and their families, the second generation of Hibakusha, atomic bomb survivors, Armenian survivors of the Turkish Genocide and their families, Native American survivors of the American Indian Holocaust, Iranian Baha'i survivors of persecution in Iran, and others (Danieli, 1998).

Nichols' (1976) model would explain the phenomenon of violence among African American male youth as a result of a distortion and oppressive alienation of these youth from their fundamental philosophical ideology namely, their "relationship" based cultural axiology. This alienation often has an adverse impact upon African American adult male development as this relates to manhood and masculinity and therefore upon their concept of respect.

\section{The Trauma Response: African}

\section{American Males}

Like Jamal, many African American males are exposed to violence, become victims and commit violent activities as reflected in the survey research study by the Community Mental Health Council of Chicago (Bell \& Jenkins, 1993; DuRant 
et al., 1994). The theoretical pathways discussed above will need to be linked together, if practitioners are to find a better way to understand the adaptive reasoning and coping strategies that grow out of the broad realities of poverty and social oppression for African American males. For example, in the case of Jamal he was repeatedly exposed to violence, interacted with adults with substance abuse and criminal justice involvement, and was assaulted and emotionally shut off from a mother he admired; consequently he did anything to secure her attention, even if it was negative. This neglectful, emotionally abusive and unsupportive home situation presents trauma to the youngster; if we have learned anything from Buchanan, and Simons and Johnson (both cited in Danieli, 1998), maltreatment and domestic violence and trauma are not strangers to one another. So how does a youngster like Jamal cope with these issues, and how can we understand the sociocultural aspects of coping with violence from the standpoint of the theories of human behavior described above? In other words how can we see Jamal from each theoretical iens and then integratively?

According to psychodynamic theory, Jamal's situation involves the major characteristics which comprise unresolved pain and loss. First, he is constantly reminded of the trauma associated with violence at home and in his community. Second, where he lives is a constant reminder of his insecure place in life. He lives in neighborhoods with housing stock that is decaying and the property value is comparably low. He has witnessed, experienced, and committed violent actions. Third, he carries these images and memories with him daily as he walks to school 
trying to figure out ways of maintaining his safety. Fourth, if he is either confronted with the threat of eminent danger or presented with an opportunity to hurt someone or to gain something of value and a level of satisfaction and respect from his peers, then he is likely to commit the violent act. This constant exposure to violence, the lack of caring and nurturing adults and the presence of substance users and people with criminal justice involvement increases the risk of drug use by youth and participation in violent activities (Briggs, Miller, Sayles, Tovar, \& Dozier, 1997).

From a psychodynamic point of view, Jamal's situation can be viewed as a classical response to injury and assaults on the ego development of youngsters, especially for African American male youth. He and other males are seeking the supports and gratification to the self in situations that threaten their definitions of their masculinity, self worth, and respect. They exist in home, school and community environments where they have to keep on their guard and constantly looking out for potential harm and danger to their safety. No wonder such youth may have problems with aggression; they keep up a constant vigilance and are preoccupied with issues of fear, safety, and need for approval and acceptance. The reality of no support or "love" available to them through primary institutions such as home and school leaves them no legitimate place to secure ego gratification. So they rely on defense mechanisms as a basis for seeking supports through alternative means to buttress the injury and trauma associated with their school, home, and community situation. They do this by linking to peer groups or existing vice-prone 
subcultures that become a substitute family providing all the resources, training, and support necessary to feel safe, respected and included.

From a Social Learning perspective, the main focus here is on how the violent behavior is facilitated, encouraged, and ultimately maintained by African American males. Mattaini and Thyer's (1996) perspective illustrates this point of view. As indicated above, the African American male who commits violent crimes does so as a function of reducing stress and physiological arousal, seeking material and economic gains, and/or reinforcement from peers and family members, power and respect through increasing the fear by others of being harmed, injured, or victims of criminal activities.

The manner in which the youngster is taught to secure the consequences of material, emotional, social, or personal satisfaction provides a window for understanding the influence of his peer and home environments. In the case of Jamal, he eventually became a source of fear as he gained control over his family and others in the community. He learned this by watching how his mother evoked fear in him and others, and through the experience of his peers as they committed and were able to secure personal and economic gains for their actions.

From the Sociocultural perspective, the manner in which the African American male was socialized as a young man, the stressors of being African American, the repeated episodes of deprivation and exposure to violence, all place him at risk of developing violent thoughts and actions to overcome the realities and consequences of institutional racism and oppression and not feeling legitimate. The 
African American males that fail to conform to the rules and laws of American systems and institutions are those that recognize that they have not been factored into the social, cultural and economic future of the society. The American Dream allowed voluntary immigrants historically to work their way into mainstream European society, with all the rights and privileges afforded that position, whereas African involuntary immigrants i.e., (slaves) were constitutionally labeled as three fifths human by virtue of their skin color alone and thus, forever outside of the rights and privileges associated with being white. This served as a disincentive for blacks to conform to the established system.

Given the nature of oppression as described above, it is now necessary to explicate how this dynamic may play out in relationships between some African American males. Explaining the psychological, behavioral, and relational aspects of trauma experiences for African American males requires a sociocultural framework as a context. Nichols' model which embraces the values of relationships through domains such as person to person, person to object and person to group provides the necessary schema as illustrated in Table 1. As suggested early on in this chapter by Mattaini, Twyman, Chin, and Lee (1996), the injury to African Americans and the experience of hostile environments as well as the presence of immediate supports and positive reinforcement for violence may lead to violence as discussed below.

Based on Nichols' (1976) model, in the person to person context, it is postulated that African American male youth with high degrees of psychological, 
emotional, social, and economic deprivation need to know that their own sense and perception of respect is not violated, given the fact that all things are not equal for them. In situations where their sense of respect is threatened by people not recognizing, accepting or following the code of conduct defined as respect, then the psychological factors or ingredients necessary for violence are in place.

Table 1

The Axiological Model of Inquiry

\begin{tabular}{llll}
\hline AXIOLOGY & PSYCHODYNAMIC & BEHAVIORAL & RELATIONAL \\
\hline PERSON-PERSON & $\begin{array}{l}\text { Unapproved, not } \\
\text { recognized, feels } \\
\text { disrespected }\end{array}$ & $\begin{array}{l}\text { Need to feel safe, } \\
\text { cognitive dissonance }\end{array}$ & $\begin{array}{l}\text { Hypersensitive about } \\
\text { shame }\end{array}$ \\
PERSON-OBJECT & $\begin{array}{l}\text { Self doubt about } \\
\text { being good enough }\end{array}$ & $\begin{array}{l}\text { Seeks false images of } \\
\text { success and } \\
\text { achievement }\end{array}$ & $\begin{array}{l}\text { Uses illicit means to } \\
\text { secure positive } \\
\text { symbols }\end{array}$ \\
PERSON-GROUP & $\begin{array}{l}\text { Seeks alternative } \\
\text { ways of securing } \\
\text { acceptance and } \\
\text { inclusion }\end{array}$ & $\begin{array}{l}\text { people not involved in } \\
\text { the group network }\end{array}$ & $\begin{array}{l}\text { Feels undermined by } \\
\text { non-group members } \\
\text { and society }\end{array}$ \\
\hline
\end{tabular}

How disrespect is acted upon violently has been explained previously within an applied behavioral perspective. The cognitive perceptions which accompany the need to maintain respect via social approval even if violence becomes necessary, include the need for feeling safe, accepted and approved as a person not to get in trouble with, and a false bravado of "being bad." In predominantly white 
environments the African American male youth may carry this code of conduct and the perception that whites tend to undermine them at first opportunity.

To cope with the deprivation associated with being a young African American male along with the other risk conditions that may be present (such as single parent home, many siblings, perhaps uncle, aunt, cousin or grandparent that has some background of criminal justice episodes as well as the presence of alcoholism in the family of origin) and few resiliency supports, these particular youth use relationships which are based on codes of conduct that define normative and unacceptable behaviors compared to what has been portrayed by many theorists as typical adolescent behavior. These particular youth are hypersensitive about "being clowned" in other words, publicly embarrassed or verbally attacked to the point of humiliated. They place higher value on protecting their peers, "homies," because they believe their friends to bring a sense of security and safety.

In the person to object context, the African American male youth are not ignorant of what society advertises, promotes, and values day to day. These youth want and feel that they are entitled to the same access and goals as they perceive others having. Dissonance occurs when access to these material and status based resources are out of their reach legitimately. Thus, these youth may doubt the fact that they could defer receiving these items until they are able to buy or secure these items through employment or gifts. These youth doubt their capacities to operate within the legitimate world and create different symbols as markers of achievement. 
As discussed earlier in the review of different classifications of violence, the presence of economic, social, and emotional deprivation are antecedents for violence. The acquisition of material things even by force is believed to insure admiration from others. Thus, the presence of a desired object and the assessed capacity to dominate an opponent and get recognition from fellow onlookers are the ingredients for some episodes of interpersonal violence. In essence, he wants what they have and the respect of others. This is one explanation of the association between securing material and economic gains, physiological and social recognition and violence.

In the person to group context, the African American male youth will not inform his parent of wrong doing by others, and he will be only loyal to his identified group of peers. To ward off intimidation and feeling humiliated by members from other groups, the African American male maintains commitment to his peers so that they will provide protection and support. In predominantly white environments, these youth tend to feel out of place, and to be intimidated about being understood. Black youth often do not feel they are accepted by their white peers and will not work hard at being included. Consequently they will withdraw and isolate themselves. African American male youth who use their black peer groups primarily as a foundation of values, nurturance and socialization have formed a brotherhood which connects them with those who share their sociocultural "likeness." Ward (1995) explained: 
During Adolescence, the need to identify strongly with a sense of peoplehood is heightened for African Americans by a consciousness of belonging to an ethnically and culturally distinct group that has a shared experience of racial discrimination and social oppression (Ward, 1989). Thus, their racial identity is comprised of an awareness of shared group characteristics and history, as well as by the experience of shared racial discrimination and oppression. To have such a collective identity is to know that one is not alone, that tone is inextricably connected to others and embedded in a network of interdependent relationships within the African American community. (p. 180)

So while they are with their peers, they do whatever their peers are doing, and when they are in environments without their peers, they tend to isolate, withdraw, and find others of like-mindedness or similar circumstances.

African American youth are in need of a socialization process that equips them with knowledge and understanding of the racial hostility and consequent discriminatory practices that go along with it. The absence of racial socialization leaves these youth to find alternative and sometimes aberrant approaches and philosophies for coping with day to day hassles and struggles.

\section{Post Traumatic Slave Syndrome (PTSS):}

\section{A New Theoretical Formulation}

In light of the cumulative and continued stressors experienced by African American communities, viewing such stress in light of Post Traumatic Stress Disorder (PTSD) is appropriate (American Psychiatric Association, Diagnostic and Statistical Manual of Mental Disorders, 4th ed. [DSM-IV], 1994). Although PTSD has generated profound interest, the condition described above does not meet the criteria of PTSD. 
PTSS Theory states that Africa Americans sustained traumatic injury as a direct result of slavery and continue to be injured by traumas caused by the larger society's policies of inequality, racism, and oppression. Another aspect of the injury occurred as a result of the destruction of the African culture (i.e., belief systems, customs, and values). When Africans arrived on this continent, families were often torn apart and the people were separated from their various groups or tribes. The "relationship" which was the foundation of their historical survival as well as their primary axiological construct or "value system," was threatened. Although the Africans survived the sudden violent disruption of family and home through resilience as demonstrated in the reconstruction (albeit fragmented) of their cultural values and customs, they sustained unmeasured mental, emotional, and physical damage. The recent 1997 unearthing of a slave cemetery in Washington, DC revealed startling evidence that slaves suffered physical injuries that have been rarely seen in recent history, injuries which were the result of extreme exertion and physical deprivation. National Geographic (Face to Face, 1997) reported that:

. . . Blakey's five-year study of the remains of 427 people shows that nearly half died by age 12 . All lived hard lives; 75 percent of the men and 65 percent of the women had telltale evidence of torn muscles or fractures caused by carrying heavy loads. One child had two such fractures, dental defects indicating malnutrition or disease, and signs of anemia. "We wondered how this child made it to the age of six," he says ... (p. 75)

Additionally, the institution of chattel slavery forced Africans to integrate the ethnic ideology of their captors which led to what can be described as a "cultural dissonance," a feeling of disharmony and psychological conflict resulting 
in a loss of identity and self esteem. Thus, multitudes of African Americans learned to function within a system which was at variance with their traditional customs, values and needs.

PTSD and Post Traumatic Slave Syndrome (PTSS) are different concepts. PTSD is a clinical diagnosis that when treated with medication, counseling, and other supports is a problem that can be controlled. Yet, the etiology of PTSS as a condition is inextricably linked to the social-psychological-environmental factors of oppression, racism, and other stressors of human design.

Many psychological journals, articles and books have been written with elaborate details of the symptoms of PTSD and the causes and treatment of this disorder. Individuals and groups said to suffer from this disorder include victims of rape, war veterans, holocaust survivors, and their children, victims of incest, heart attack victims, natural disaster survivors, and victims of severe accidents (DSM-IV, 1994). However, absent from this list are the African American slaves and their offspring. The absence of any therapeutic intervention during or after the advent of slavery would suggest the PTSD among slaves most likely resulted, but went untreated.

The direct trauma of slavery occurred long ago, perhaps too long ago to warrant diagnosing current African Americans with PTSD. PTSS theory proposes that residual stress-related effects were passed along through generations. Theodore Lidz (1963) wrote: 
Each society has a vital interest in the indoctrination of the infants who form its new recruits. It lives only through its members, and its culture is its heart which must keep pulsating. Without it, its members are rootless and lost. They must be so raised that the culture exists in them and they can transmit it to the next generation. It is a task that every society largely delegates, even though unwittingly, to an agent--the family. (p. 19)

The method of transmission has occurred on several levels, the family level, the community level and the societal level. In addressing the family level of transmission Comer (1980) stated:

The slave family existed only to serve the master and in order to survive physically, psychologically and socially the slave family had to develop a system which made survival possible under degrading conditions. The slave society prepared the young to accept exploitation and abuse, to ignore the absence of dignity and respect for themselves as blacks. The social, emotional and psychological price of this adjustment is well known. (p. 47)

PTSS theory suggests that the price paid included self-destructive behaviors as identified in symptoms of PTSD listed in the Diagnostic and Statistical Manual of Mental Disorders Revised Edition-IV (DSM-IV, 1994): (a) feeling of detachment or estrangement from others, (b) restricted range of affect, e.g., unable to have loving feelings, (d) sense of foreshortened future, e.g., does not expect to have career, marriage, or children, or a long life, (e) irritability or outbursts of anger, unpredictable explosions of aggressive behavior, (f) difficulty concentrating, (g) hypervigilance, and (h) exaggerated startle response.

Thus, the individuals and families that survived the slave experience reared their children while simultaneously struggling with the above mentioned symptoms. The children lived and learned the behaviors and attitudes of their injured and 
disturbed parents. Albert Bandura (1997) suggested that human beings do not always learn through direct instruction but rather through vicarious learning. The individual problems are compounded when there are additional psychiatric problems and neurological impairment (Monahan, 1981).

The second method of transmission is through the "community." During slavery the community was a suppressed and marginalized group. Today, the African American community is made up of individuals and families who collectively share differential anxiety and adaptive survival behaviors resulting from prior generations of African Americans who suffered from PTSD. The community serves to reinforce both the positive and negative behaviors through the socialization process. For example, in the 1940s according to Comer (1980) families frequently destroyed any signs of aggression in their children, particularly the male children. It was an acceptable and expected practice in African American communities to severely beat unruly boys so that they would never make the mistake of standing their ground with a white person in authority. Comer further states: "Given the overt suppression possible and practiced, such preparation and reaction was adaptive and necessary for black survival. It was harmful to black self-esteem and group esteem and social development, however" (p. 49).

Contemporary examples of community level transmission can be readily seen in the behavior of black mothers in public and private settings like banks and professional buildings. African American mothers will insist that their children, often toddlers, or preschool aged youngsters, not move from their side throughout 
the entire time they are conducting their business. If the child should attempt to stray, which is normal for young children to do, he or she will be severely reprimanded by the mother. At the same time the child witnesses white children freely running about without much notice or incident. Frequently, if there is another black woman in the same bank or place of business, she will, in an effort to support the mother and assuming the mother would wish her to do so, strongly admonish the child to stay by the mother's side. This is another example of community level adaptive behavior which borders on harmful. The children are given the message that they cannot explore; perhaps they will cause some trouble or harm to their mother. At the same time these youngsters perceive that it is permissible for white children to run, play, and explore. The interaction with the larger society has occurred at all the levels of transmission, adding consistent and enduring trauma through policies of continuing inequality, discrimination, and scarcity of resources, coupled with crass materialism and a mass communication system which allows everyone to see the stark disparity between the "haves" and the "have nots." New policies such as Welfare Reform and changes in affirmative action serve to reopen the wounds making it increasingly difficult to fulfill the societal expectation or individual and group aspiration. Individuals, especially young people, often become frustrated and lose hope and resort to alternative means inclusive of criminal activities and violence to get their needs met. Thus, based on PTSS theoretical formulation, African American male violence is only one of many symptoms of transgenerational trauma resulting from oppression. 
This particular trauma involves social psychological injury and a failure to conform as reflected in the above discussion on PTSS.

The problem of African American male youth violence is broad as well as complex. The issues that surround it are only partially understood through existing explanatory theories such as: psychodynamic, social learning and sociocultural theories. This research utilizes these theories together with a new theoretical framework (Post Traumatic Slave Syndrome) which takes into account multigenerational trauma. Many studies of African American male youth violence have focused upon environmental conditions of poverty and crime as predictors of future violence. Few studies have focused upon the relationship of violence among this population to socioculturally adaptive mechanisms acquired as a result of sustained psychological multigenerational trauma. Thus, there is a need to answer the questions regarding how exposure to violence along with historical trauma, racial socialization and the daily hassles associated with living in urban settings as a racially oppressed group relate to violence. The answers to these questions may help to determine the factors which relate to and influence African American male youth violence and more importantly, identify those factors which serve to protect these youth against such behaviors.

Research about African American male youth violence must consider the historical injuries sustained by this group and their efforts to adapt to American societal expectations. While the social problem of violence evokes serious concern and attention from policy makers, practitioners and others, all too often the public 
fear surrounding the issue of violence elicits feelings of urgency to solve the problem and seldom allows for a thorough investigation into the important sociocultural factors critically associated with the problem. 


\section{CHAPTER II}

\section{RESEARCH QUESTIONS AND HYPOTHESES}

This dissertation is an exploration of five specific research questions, each of which centers upon a variable believed to predict violent behavior in African American male youth. The first three questions address stressors experienced by African Americans and the fourth and fifth questions, which represent the core of the dissertation, focus upon sociocultural characteristics which may lead to violence.

Many African American male youth live in environments that produce stressors such as: fear for safety, pressure from drug dealers and addicts, confrontations with strangers, being in dirty and unhygienic surroundings, and hearing gunshots and sirens throughout the day and night. These stressors present a dismal and hopeless daily experience for the young people leading to frustration and anger and a feeling that their lives are out of control. Violence provides these youth with a vehicle to gain control and gives them a false sense of mastery over their chaotic environments. This perspective is consistent with Chestang's (1972) theory of the development of adaptive characteristics among black males which includes the formation of several types of character behaviors: the depreciating, the integrative and the transcendent. For violent youth the depreciating character 
demonstrates an antisocial response to this stressful environment while others may adopt the more prosocial integrative and transcendent characters.

The first three questions address the relationship between the types of stressors commonly experienced by African American male youth and their use of violence. The stressors the study is focused upon are the following: violence witnessing, violence victimization, and daily urban hassles.

For all questions, the use of violence will be measured using the Use of Violence Scale adapted by DuRant et al. (1994). This scale uses items from the Youth Risk Behavior Survey (Centers for Disease Control, 1999) and items from the Denver Youth Study Self Reported Delinquency Questionnaire (Huizinga, Esbensen, \& Weiher, 1991).

\section{Research Question One}

What is the relationship between the witnessing of violence by African American male youth and their reported use of violence?

Violence has so permeated the lives of some African American youth that they no longer see a future for themselves. A noteworthy article in the Washington Post (Brown, 1993) reported that children in Washington, DC neighborhoods were preparing to die. The future appears so dismal to these children that some have begun to plan their funerals when they are as young as 10 years old. In the same article, Douglas Marlowe, a psychologist at Hanemann 
University Hospital, described this fatalistic behavior as abnormal adolescent development characterized by feelings of extreme hopelessness. "They are not trying to conquer death anymore. They are now turning themselves over" ( $p$. A13).

Given the constant exposure to violence in the lives of other people, these youth may develop aggression as a means to survive and buttress themselves against the threatening environment surrounding them. The witnessing of violence by older African American youth was found to be a significant predictor of depression (Fitzpatrick \& Boldizar, 1993).

Additionally, African American males are often diagnosed as having antisocial personality disorder or having sociopathic tendencies when they are actually experiencing depression with suicidal ideation which may have been brought on by witnessing of violence. Some African American psychologists are calling the behaviors commonly identified as antisocial (particularly violent behaviors) and homicidal as a form of "invited suicide" (Davis-Russel, 1990).

Therefore, the first hypothesis is that the greater the exposure to violence by witnessing, the greater the reported use of violence by African American male youth. The Survey of Exposure to Community Violence-Violence Witnessing Self Report Version (Richters, 1990) was used to assess the level of violence witnessed by these youth. 


\section{Research Question Two}

What is the relationship between the level of victimization of African American male youth and their reported use of violence?

Research has supported the supposition that individuals that are the victims of violence, particularly when they are young, have an increased likelihood of exhibiting violence toward others later in life. Bell and Jenkins (1991) identified the far reaching effects of violence on the lives of children:

Violence that touches children has consequences far beyond the individual victim, eventually having an impact on the quality of life in the black community. In addition to the lost resources of a fully functioning member with a healthy mind and body, exposure to violence creates an individual more likely to engage in future violence and other antisocial acts. (p. 179)

Being the victim of violence produces anger and fear which may result in an individual retaliating against the perpetrator or others. Striking back with violence is often perceived as a suitable response to being victimized by others. These youth learn first hand that violence is a necessary aspect of daily life and survival in the inner-city (Bell \& Jenkins, 1991).

Given this research it is predictable that African American male youth having themselves experienced being victimized would have a greater propensity toward violent behavior. Therefore, the second hypothesis is that the greater exposure to violence by victimization, the greater the reported use of violence by African American male youth. The Survey of Exposure to Community 
Violence-Violence Victimization Self Report Version (Richters, 1990) was used to assess the level of violence victimization experienced by these youth.

\section{Research Question Three}

What is the relationship between the stress caused by urban hassles and the reported use of violence by African American male youth?

Urban hassles often become risk factors which influence whether or not a young person resorts to violence. Young people have an increased risk of becoming violent when they become angry, frightened, or threatened as a result of urban hassles. Some of these risk factors arising out of urban hassles (American Psychiatric Association, 1996; Prothrow-Stith, 1994; Walker, 1995) include:

- Poverty, which affects one in every five children

- Domestic violence, which may take the form of neglect, physical abuse, sexual abuse, or emotional maltreatment of children (children are also profoundly affected by witnessing violence in the home, which can draw them into a cycle of violence)

- Exposure to violence in society and the media, which researchers have found causes some children to become desensitized to violence and others to become more fearful of violence

- Easy access to guns or other weapons

- Ethnic or racial conflict, which creates tension that can quickly escalate into violence 
- Gangs, which are both a cause and a consequence of violence and which adopt violence as a way of life

- Substance abuse, which shares many of the same risk factors as violence.

Given this research, the third hypothesis is that the greater the level of daily urban hassles experienced by African American male youth, the greater their reported use of violence. The Urban Hassles Scale (Miller, 1999) was employed to assess the level of urban hassles experienced by these youth.

\section{Research Question Four}

What is the relationship between racial socialization and the reported use of violence by African American male youth?

Every African American child eventually comes to learn that he or she holds a unique position in the American social structure, a position that relegates one to a position of staggering inequality. Race and Class are the defining factors that determine the status an individual has in America. Cole (1999) stated:

The consequences of the country's race and class divisions are felt in every aspect of American life, from infant mortality and unemployment, where black rates are double white rates; to public education, where the proportion of black children educated in segregated schools is increasing; to housing, where racial segregation is the norm . . . Racial inequality remains to this day the most formidable of our social problems. (p. 4)

Hacker (1992) exposed the underlying reasons why and how African Americans have been assigned to a position of inferiority and why as a group they continue to experience inequality. Ingrained racial prejudice serves to benefit 
whites while it subjugates blacks. This situation creates a disincentive for finding a fair solution to the inequality. Hacker stated that blacks have learned to live with a real and imposed segregation that is more pervasive and acute than any other form of human division.

Grier and Cobbs (1969) commented on the hassles associated with acquiring manhood in American society:

Thus the black boy in growing up encounters some strange impediments. Schools discourage his ambitions, training for valued skills is not available to him, and when he does triumph in some youthful competition he receives compromised praise, not the glory he might expect. In time he comes to see that the society has locked arms against him, that rather than help he can expect opposition to his development, and that he lives not in a benign community but in a society that views his growth with hostility ... For the inner psychological obstacles to manhood are never so formidable as the impediments woven into American Society. (p. 49)

Thus, African American male youth are socialized to understand the obstacles that are associated with being born black. They learn early on about the systemic racism that surrounds them and the skills and coping mechanisms necessary for their survival. Through the guidance of family members and the support from the community, black children learn that despite the social barriers they are able to excel and prosper. Socialization occurs as families provide children with a historical and cultural map of the African American experience that describes how they have survived many adverse conditions beginning with slavery. 
They learn how the belief in God and extended family has served to strengthen and insulate them from the negative effects of racism and discrimination.

Additionally Stevenson (1994a) postulated that racial socialization is one of the ways that cultural values are transmitted and can provide children with a more positive perception of themselves. Stevenson and others concluded that racism is an intrinsic part of the fabric of American society that cannot be ignored and that racial socialization by parents can act as a protective factor for their children. When one's group has been stigmatized by the majority culture's negative appraisals it is encouraging for African American youth to be told by members of their own group that the assessment of the dominant culture is fueled by inaccuracies and bias and to be cautioned not to internalize this perception. Within the group youth are given reassurance through acknowledgment of the strengths and accomplishment of their culture.

The fourth hypothesis is that the more racial socialization these youth receive, the less their reported use of violence. The Scale of Racial SocializationAdolescent Version (Stevenson, 1994b) was used to assess the level of racial socialization these youth received.

\section{Research Question Five}

What is the relationship between issues of respect and the reported use of violence by African American male youth? 
The decision of African American male youth to be violent or peaceful is largely a function of self worth. African American male youth define self worth by variables of respect and power. Power is defined by the ability to manipulate and influence the forces that control one's existence namely; resources (i.e., food, shelter, work, protection of self, and others), and knowledge (i.e., meaningful and necessary information for access to needed resources).

Respect has been an essential part of African and African American culture. The respect for adults and elders was demonstrated in numerous ways. One way was to acknowledge them first with a greeting upon entering a room or by addressing them by appropriate titles. During slavery Africans were not given titles of respect by whites. They were never addressed as "ladies" or "gentlemen," 'Mister,' or 'Miss' or "Mrs.," so they conferred their own designation of respect. They addressed one another as "Big Mama," and "Big Daddy," "Ma-dea," "Sister" or "Brother" to convey honor.

Similarly, as a continuing legacy of slavery some African American male youth today have recognized that the society around them does not respect them and have developed elaborate and antisocial ways of defining and demonstrating levels of respect. These artificially constructed rules for showing respect carry with them severe penalties for the slightest deviation from the established norms and transgressions are often met with violence. Therefore, it is expected that African American male youth with antisocial attitudes toward respect would be 
more likely to act violently toward others that they feel have shown them any level of disrespect, and later be exonerated for any wrong doing. Conversely, African American young men that have prosocial attitudes would be less likely to act violently as a result of feeling disrespected. The fifth hypothesis is that the more antisocial attitudes toward respect these youth have, the greater their reported use of violence. The African American Respect Scale-Male Adolescent Version has been developed to assess the youths' attitudes toward respect (Leary, 1999).

\section{Summary Diagram}

Figure 1 presents a summary diagram which illustrates the hypothesized relationships among the six variables focused upon in this study. The stress variables believed to predict higher levels of (6) the use of violent behavior in African American male youth with higher levels of their presence are: (1) violence witnessing, (2) violence victimization, and (3) daily urban hassles. The sociocultural variables believed to promote resilience and therefore, predict (6) less use of violence are (4) racial socialization and (5) prosocial attitudes toward respect.

Additional relationships among these six variables are explored after the psychometric properties of the Respect Scale have been established. 


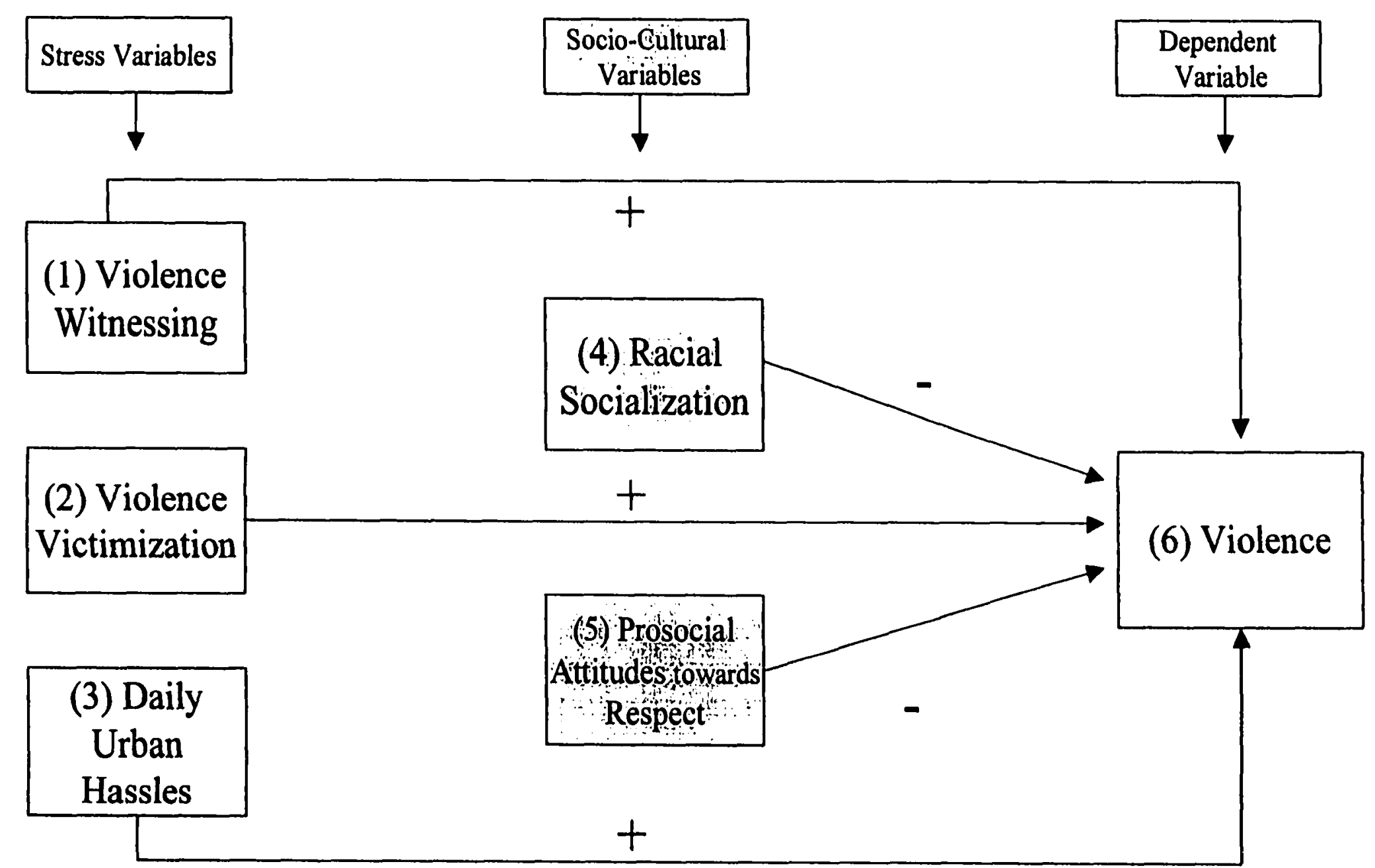

Figure 1. Summary diagram of predictors of African American male youth use of violence. 


\section{CHAPTER III}

\section{RESEARCH DESIGN AND METHODOLOGY}

This dissertation is an exploratory research study that investigated key variables in the sociocultural framework that practitioners may find of particular use as they plan assessments and treatment with violent African American male youth. Thus, the research has multiple features including: (a) the relevance of key stressors which trigger violent behavior, and (b) the core focus on the significance of sociocultural characteristics associated with violent African American male youth. Thus, the purpose of this dissertation study is dual: (a) to determine the environmental context of violent behaviors among young African American males and (b) to investigate sociocultural protective factors which may assist African American male youth to integrate with the rest of society while others withdraw and become violent.

\section{Design}

This dissertation is a cross sectional survey of African American male youth in the Portland, Oregon metropolitan area in cooperation with The Portland House of Umoja residential facility, McLaren Youth Correctional Facility, Donald E. Long Youth Correctional Facility, and the Bridge Builders Gentlemen's Rites of 
Passage Program. The study included two groups of African American male youth with ages 14 to 18 . The first group was comprised of incarcerated individuals who have committed violent crimes as identified by program administrators from one community based residential program and two correctional residential programs. The second group was made up of non-incarcerated African American male youth from the Bridge Builders Gentlemen's Rites of Passage Program, a youth development program supporting prosocial behavior. Using an on-site administered written survey, anonymous youth were asked to provide information on their behaviors and experiences.

The survey collected data to investigate five basic research questions:

1. What is the relationship between the witnessing of violence by African American male youth and their reported use of violence?

2. What is the relationship between the level of victimization of African American male youth and their reported use of violence?

3. What is the relationship between the stress caused by urban hassles and the reported use of violence by African American male youth?

4. What is the relationship between racial socialization and the reported use of violence by African American male youth?

5. What is the relationship between issues of respect and the reported use of violence by African American male youth? 
Sample

The sample consisted of African American male youth in Oregon ages 14 to 18. Participants were identified by one of four organizations. The Portland House of Umoja residential facility is a culturally based rehabilitative treatment program located in the black community. The goal of the program is to reintroduce readjusted youth back into the community. McLaren Youth Correctional Facility and Donald E. Long Youth Correctional Facility, are facilities designed to incarcerate delinquent juveniles. The Bridge Builders Gentlemen's Rites of Passage is a program specifically designed to support and assist African American males to be successful academically, socially and personally. The two groups were selected to represent a range of violent behavior for the purposes of this study. Administrators in each of the programs agreed to promote participation in this study through their organizations. Although 205 surveys were collected, 5 were eliminated due to incompleteness or ineligibility.

A formal letter was sent to each organization that included information about the purpose of the study, about how the information was to be used, and about survey procedures. Accompanying the letters were informed consent forms to be filled out by the participating organization, the participating subjects, and where appropriate the parents of the subjects. Upon each organization's agreement 
to participate, group sessions for administration of surveys were scheduled by the principal investigator.

\section{Procedures}

Data collection was carried out in conjunction with participating organizations. Two separate but related data collection procedures were used for incarcerated youth and non-incarcerated youth. The incarcerated youth were those recruited from The Portland House of Umoja residential facility, McLaren Youth Correctional Facility, and Donald E. Long Youth Correctional Facility. The nonincarcerated youth were recruited from the Bridge Builders Gentlemen's Rites of Passage Program.

\section{Data Collection: Incarcerated Youth}

The principal investigator obtained formal written consent from the appropriate administrators from each correctional facility who are considered the legal guardians of the youth. The administrators were asked to have the staff inform the residents about the opportunity to participate in a study being conducted by a graduate student from the Portland State University Graduate School of Social Work about the experiences and behaviors of African American male youth. Staff scheduled sessions at which 10 interested youth met with the researcher. All sessions were held within the facility and took approximately one hour. 
Refreshments were provided. Correctional Facility Staff were present immediately outside of the room used for data collection.

The researcher explained to the youth what the study covered and what they were specifically requested to do. They were told that the survey was anonymous, that they would be free to participate or not, and their decision would not affect their status or services in the institution where they resided. The youth received two copies of a written consent form which was explained to them by the researcher. All youth who decided to participate returned one copy of the consent form to the researcher and kept one copy for themselves.

The principal investigator administered the Survey of African American Male Youth Experience and Behavior in a group format. She distributed a survey booklet to each participant. The youth were directed to open the booklet and complete the survey one section at a time as she instructed them. She read the directions for each section and answered any questions the participants had. Due to the anticipated low reading level of the incarcerated youth, the researcher read each question aloud and gave the youth time to respond. After the youth completed the survey, open-ended questions were administered. They received a $\mathrm{t}$-shirt for their participation in the study.

\section{Data Collection: Non-Incarcerated Youth}

The principal investigator through the cooperation of the Bridge Builders Gentlemen's Rites of Passage Program addressed the parents of the program 
participants at several of their scheduled meetings where she explained that she was a graduate student from Portland State University Graduate School of Social Work doing research about the experiences and behaviors of African American male youth. The parents who agreed to their child's participation were given a consent form which they were asked to fill out. The researcher collected the consent forms and asked administrators from the Bridge Builders Gentlemen's Rites of Passage Program to inform the youth whose parents have given consent about the opportunity to participate in a study of the experiences and behaviors of African American male youth. Staff scheduled sessions at which 10 to 20 interested youth met with the researcher. All sessions were held at a facility designated by the staff and took approximately one hour. Refreshments were provided.

The researcher explained to the youth what the study covered and what they were specifically requested to do. They were told that the survey would be anonymous and that they were free to participate or not; their decision would not affect their status or services in the Bridge Builders Gentlemen's Rites of Passage Program. The youth received two copies of a written consent form which was explained to them by the researcher. Participants returned one copy to the researcher and kept one copy for themselves.

The principal investigator administered the Survey of African American Male Youth Experience and Behavior in a group format. She distributed a survey booklet to each participant. The youth were directed to open the booklet and complete the survey one section at a time as she instructed them. She read the 
directions for each section and answered any questions the participants had. The researcher read each question aloud and gave the youth time to respond. The open-ended questions were administered separately. After the youth completed the survey, they received a t-shirt for their participation in the study.

\section{$\underline{\text { Data Procedures }}$}

Upon completion of the surveys at a particular organization they were locked in a secure cabinet in the office of the principal investigator. The principal investigator checked the surveys for completeness and prepared them for submission for data entry. Only the principal investigator and her research assistants viewed the surveys during data analysis. Access to the raw data remained limited to the project staff. Informed consent forms are locked in a file cabinet.

Three surveys from the incarcerated population of youth surveyed were eliminated because the youth did not meet the age requirement and two surveys from the non-incarcerated youth surveyed were eliminated because one of the youth did not meet the age requirement and the second youth failed to answer any of the questions on the survey.

\section{Measurements}

The Survey of African American Male Youth Experience and Behavior consisted of seven sections: (a) demographic measures, (b) daily urban hassles, 
(c) prosocial attitudes toward respect, (d) racial socialization, (e) violence

witnessing, ( $f$ ) violence victimization, and $(\mathrm{g})$ use of violence. The final part of the survey consisted of the following two qualitative open-ended questions, which were distributed and administered separately:

1. If you and your friends have felt disrespected at some time in your life, why do you think it happened?

2. Why do you think people like you are disrespected?

For a summary of instruments used refer to Table 2.

Table 2

Instruments Used in African American Youth Survey about Beliefs and Experiences

\begin{tabular}{|c|c|c|c|}
\hline Variable Name & Instrument Name & Source of Instrument & \# of Items \\
\hline \multirow[t]{3}{*}{ Use of Violence } & Use of Violence Scale & DuRant et al. (1994) & \\
\hline & --Youth Risk Behavior Survey & $\begin{array}{l}\text { Centers for Disease } \\
\text { Control (1999) }\end{array}$ & 2 \\
\hline & $\begin{array}{l}\text {--Denver Youth Study Self } \\
\text { Reported Delinquency } \\
\text { Questionnaire }\end{array}$ & $\begin{array}{l}\text { Huizinga, Esbensen, \& } \\
\text { Weiher (1991) }\end{array}$ & 5 \\
\hline Violence Witnessing & $\begin{array}{l}\text { Survey of Exposure to } \\
\text { Community Violence--Self } \\
\text { Report Version }\end{array}$ & Richters (1990) & 11 \\
\hline $\begin{array}{l}\text { Violence } \\
\text { Victimization }\end{array}$ & $\begin{array}{l}\text { Survey of Exposure to } \\
\text { Community Violence--Self } \\
\text { Report Version }\end{array}$ & Richters (1990) & 12 \\
\hline Daily Urban Hassles & Urban Hassles Scale & Miller (1999) & 12 \\
\hline Racial Socialization & $\begin{array}{l}\text { Scale of Racial } \\
\text { Socialization-Adolescent } \\
\text { Version }\end{array}$ & Stevenson (1994b) & 45 \\
\hline $\begin{array}{l}\text { Prosocial Attitudes } \\
\text { Toward Respect }\end{array}$ & $\begin{array}{l}\text { African American Respect } \\
\text { Scale-Male Adolescent } \\
\text { Version }\end{array}$ & Leary (1999) & 20 \\
\hline
\end{tabular}




\section{CHAPTER IV}

\section{RESULTS}

\section{Participant Characteristics}

The quantitative analysis began with the determination of the frequency and distribution of demographic variables, and the major scaled variables under study.

The demographic variables of the incarcerated group and the nonincarcerated group were separately tabulated and compared, in order to detect significant differences between the incarcerated and non-incarcerated groups (see Table 3). Nominal level measures were compared using Pearson's chi-square, and interval level measures were contrasted using $t$-tests.

Individual items of the scales concerning violence witnessing, violence victimization, and use of violence were examined, and differences were sought between the incarcerated and non-incarcerated groups in exposure to and participation in violence. These are reported in the Hypothesis Testing section.

Only three demographic variables were significantly different between groups. A $t$-test of independent means revealed that the incarcerated youth were older $(M=16.4, S D=1.3)$ on average than the non-incarcerated group $(M=$ $15.8, S D=1.2$ ). Although the age difference was statistically different, in practical terms there was only about one half year difference in age. The second 
Table 3

Demographic Characteristics of Non-Incarcerated (NI) and Incarcerated (IY) African American Male Youth

\begin{tabular}{|c|c|c|c|c|c|c|c|c|c|c|}
\hline & \multicolumn{3}{|c|}{$\mathrm{NI}(n=100)$} & \multicolumn{3}{|c|}{ IY $(n=100)$} & \multicolumn{4}{|c|}{ Total } \\
\hline & $\%$ & Mean & $S D$ & $\%$ & Mean & $S D$ & $n$ & $\%$ & Mean & $S D$ \\
\hline Age* & & 15.8 & 1.2 & & 16.4 & 1.3 & & & 16.1 & 1.3 \\
\hline Highest grade completed & & 9.4 & 1.1 & & 9.7 & 1.4 & & & 9.5 & 1.2 \\
\hline Attends school program & 90.0 & & & 90.3 & & & 171 & 85.5 & & \\
\hline Father in home & 52.0 & & & 47.7 & & & 73 & 36.5 & & \\
\hline Mother in home** & 95.7 & & & 75.8 & & & 158 & 79.0 & & \\
\hline Both in home*** & 36.0 & & & 20.0 & & & 56 & 28.0 & & \\
\hline Both not in home & 4.0 & & & 12.0 & & & 16 & 8.0 & & \\
\hline Father employed & 80.4 & & & 64.7 & & & 78 & 39.0 & & \\
\hline Mother employed & 96.6 & & & 89.3 & & & 152 & 76.0 & & \\
\hline Family owns car & 90.0 & & & 90.3 & & & 174 & 87.4 & & \\
\hline Family owns home & 60.8 & & & 47.2 & & & 101 & 50.8 & & \\
\hline Most frequent ZIP code 97211 & 39.1 & & & 41.5 & & & 70 & 40.2 & & \\
\hline 2nd 97217 & 17.4 & & & 12.2 & & & 26 & 14.9 & & \\
\hline 3rd 97212 & 14.1 & & & 8.5 & & & 20 & 11.5 & & \\
\hline 4th 97213 & 5.4 & & & 11.0 & & & 14 & 8.0 & & \\
\hline 5th 97203 & 2.2 & & & 6.1 & & & 7 & 4.0 & & \\
\hline Other ZIP codes & 21.8 & & & 20.7 & & & 30 & 21.4 & & \\
\hline
\end{tabular}


variable on which the groups differed was the presence of their mother in the home. For incarcerated youth $75.8 \%$ had their mothers living in their homes but the non-incarcerated youth had $95.7 \%$ of their mothers living in their homes. This revealed a very important difference between the groups. Only around half of both groups had their fathers living in their homes.

The third variable on which the groups differed was the presence of both mother and father in the home. For incarcerated youth, $20 \%$ had both their mother and their father living in the home, but the non-incarcerated youth had $36 \%$ of both parents living in their home.

The groups differed on the variable recording the absence of both mother and father from the home. Only $12 \%$ of the incarcerated group and $4 \%$ of the non-incarcerated group had neither mother nor father living in their home. This difference, however, was not found to be statistically significant. None of the demographic variables related to socioeconomic status was significantly different for the two groups of youth. Home ZIP code areas reported by the youth were in Northeast Portland in five concentrated areas.

\section{Hypothesis Testing}

\section{Hypothesis 1: Violence Witnessing}

The first hypothesis was that the greater the exposure to violence by witnessing the greater the reported use of violence by African American male youth. In order to test the hypothesis, scores were calculated from two 
instruments: (a) the Survey of Exposure to Community Violence-Violence Witnessing Self Report Version (Richters, 1990) and, (b) the Use of Violence Scale adapted by DuRant et al. (1994).

Scores for Violence Witnessing were calculated in two ways: witnessing extent and witnessing intensity. Witnessing extent was calculated by summing the dummy coded scores for all 11 items with $0=$ never and $1=$ sometimes, often, or very often. This gave a witnessing extent score that could range from 0 to 11 using the calculation method adopted by Fitzpatrick and Boldizar (1993). The scores that were obtained from this sample of African American youth ranged from 1 to 11 ; the total mean score revealed a relatively high level of witnessing $M=$ 6.88 with $S D=2.21$. Significant differences were found between incarcerated and non-incarcerated youth on 9 out of 11 violence witnessing items (see Table 4). For all items that were significantly different, incarcerated youth reported higher levels of violence witnessing than non-incarcerated youth. The Violence of Witnessing Extent Scale was moderately reliable given that a Chronbach's $\alpha=.71$ was obtained for the entire sample.

Witnessing intensity was calculated by summing witnessing frequency scores for each item which ranged from $0=$ never to $3=$ very often. This resulted in a total witnessing intensity score with a possible range from 0 to 33 . Scores from this sample ranged from 1 to 33 ; the total mean score was 12.72 with a $S D=6.88$. Incarcerated youth had significantly higher scores on 5 out of 11 items of the Witnessing Intensity Scale as can be seen in Table 5. Although it was 
Table 4

Numbers of African American Youth Experiencing Individual Violence

Witnessing Extent Items

\begin{tabular}{|c|c|c|c|c|c|c|}
\hline \multirow[b]{2}{*}{ Variable } & \multicolumn{2}{|c|}{ IY } & \multicolumn{2}{|c|}{$\mathrm{NI}$} & \multirow[b]{2}{*}{$x^{2}$} & \multirow[b]{2}{*}{$p$-value } \\
\hline & $n$ & $\%$ & $n$ & $\%$ & & \\
\hline \multicolumn{7}{|l|}{ 1. Have you ever witnessed anyone being chased when } \\
\hline 2. Have you ever witnessed someone being hit by a & 90 & 95.0 & 90 & 90.0 & 1.80 & .179 \\
\hline member of your family? & 87 & 43.7 & 78 & 39.2 & 2.37 & .124 \\
\hline 3. Have you ever witnessed someone being hit by & & & & & & \\
\hline non-family members? & 94 & 47.0 & 82 & 41.0 & 6.82 & .009 \\
\hline $\begin{array}{l}\text { 4. Have you ever witnessed someone being beaten } \\
\text { or mugged? }\end{array}$ & 87 & 43.5 & 64 & 32.0 & 14.3 & $<.001^{*}$ \\
\hline $\begin{array}{l}\text { 5. Have you ever witnessed someone being sexually } \\
\text { assaulted? }\end{array}$ & 22 & 11.1 & 39 & 19.6 & 6.59 & -.001 \\
\hline 6. Have you ever witnessed someone being attacked & & & & & & \\
\hline $\begin{array}{l}\text { with a knife? } \\
\text { 7. Have you ever witnessed someone being seriously }\end{array}$ & 73 & 36.5 & 37 & 18.5 & 26.2 & $<.001^{*}$ \\
\hline wounded after a serious incident of violence? & 92 & 46.0 & 60 & 30.0 & 28.1 & $<.001^{*}$ \\
\hline 8. Have you ever witnessed someone being shot at? & 87 & 43.5 & 55 & 27.5 & 24.9 & $<.001^{*}$ \\
\hline 9. Have you ever witnessed a serious accident? & 90 & 45.0 & 79 & 39.5 & 4.62 & .032 \\
\hline 10. Have you ever witnessed a suicide? & 16 & 8.0 & 9 & 4.5 & 2.32 & .127 \\
\hline 11. Have you ever witnessed a murder? & 30 & 15.0 & 9 & 4.5 & 14.0 & $<.001^{*}$ \\
\hline
\end{tabular}

*Note: Bonferroni correction at $p<.05$ is $p<.005 ; N=200$. 


\section{Table 5}

Individual ltem $t$-tests of Violence

Witnessing Intensity

\begin{tabular}{|c|c|c|c|c|c|}
\hline Variable & IY & NI & $t$ & $d f$ & $p$-value \\
\hline 1. Witness anyone being chased* & .950 & .900 & 1.342 & 180.7 & .181 \\
\hline 2. Witness being hit by family* & .870 & .788 & 1.539 & 189.2 & .126 \\
\hline 3. Witness someone being hit by non-family* & .940 & .820 & 2.644 & 165.0 & .009 \\
\hline 4. Witness someone beaten or mugged* & .870 & .640 & 3.905 & 177.3 & $<.001^{* *}$ \\
\hline 5. Witness someone sexually assaulted* & .222 & .390 & -2.599 & 192.7 & .010 \\
\hline 6. Witness attacked with a knife* & .730 & .370 & 5.461 & 196.6 & $<.001^{* *}$ \\
\hline 7. Witness someone seriously wounded* & .920 & .600 & 5.686 & 154.5 & $<.001^{* *}$ \\
\hline 8. Witness someone being shot at* & .870 & .550 & 5.302 & 173.8 & $<.001^{* *}$ \\
\hline 9. Witness a serious accident* & .900 & .790 & 2.164 & 181.9 & .032 \\
\hline 10. Witness a suicide* & .162 & .090 & 1.523 & 184.8 & .129 \\
\hline 11. Witness a murder* & .300 & .090 & 3.867 & 166.0 & $<.001^{* *}$ \\
\hline
\end{tabular}

*Note: Equal variance not assumed;

**Bonferroni correction at $p<.05$ is $p<.005$. 
not significantly higher, non-incarcerated youth reported greater witnessing intensity for one item; sexual assault. This scale was also found to be highly reliable with Chronbach's $\alpha=.86$ for this sample.

The Use of Violence Extent scores were also calculated using the DuRant et al. (1994) procedure which dummy coded each of seven items with $0=$ never used that form of violence and $1=$ sometimes, often, or very often. This results in scores with a possible range of 0 to 7 . Scores from this sample ranged from 0 to 7 with the total mean score being 2.63 and a $S D=2.11$. Incarcerated youth had significantly higher scores on all 7 scale items as can be seen in Table 6 . This scale was also found to be moderately reliable with Chronbach's $\alpha=.77$ for this sample.

Use of Violence Intensity was calculated by summing use of violence frequency scores for each item which ranged from $0=$ never to $3=$ very often. This resulted in a total use of violence intensity score with a possible range from 0 to 21 . Scores from this sample ranged from 1 to 21 ; the total mean score was 4.60 with a $S D=4.76$. As predicted, incarcerated youth had significantly higher scores on all 7 items of the scale (see Table 7). With a Chronbach's alpha of .83 the Use of Violence Intensity Scale was found to be highly reliable with this sample.

In order to test the first hypothesis linear regressions were calculated in two ways: (a) with the independent variable being violence witnessing extent and the dependent variable being use of violence extent and (b) with the independent 
Table 6

Numbers of African American Youth Reporting the Use of Particular Types of Violence Through the Violence

Use Scale (Extent Calculation)

\begin{tabular}{|c|c|c|c|c|c|c|}
\hline \multirow[b]{2}{*}{ Variable } & \multicolumn{2}{|c|}{ IY } & \multicolumn{2}{|c|}{ NI } & \multirow[b]{2}{*}{$\chi^{2}$} & \multirow[b]{2}{*}{$p$-value } \\
\hline & $n$ & $\%$ & $n$ & $\%$ & & \\
\hline 1. Attacked someone you lived with & 61 & 30.7 & 37 & 18.6 & 12.1 & $.001^{*}$ \\
\hline 2. Involved in a physical fight in the past 12 months & 72 & 36.0 & 45 & 22.5 & 15.0 & $<.001^{*}$ \\
\hline $\begin{array}{l}\text { 3. In the previous } 12 \text { months received an injury in a } \\
\text { fight requiring medical care }\end{array}$ & 22 & 11.0 & 4 & 2.0 & 14.3 & $<.001^{*}$ \\
\hline 4. Been involved in a gang fight & 52 & 26.0 & 15 & 7.5 & 30.7 & $<.001^{*}$ \\
\hline 5. Carried a weapon such as a knife & 39 & 19.7 & 15 & 7.6 & 14.7 & $<.001^{*}$ \\
\hline 6. Ever carried a hidden weapon & 65 & 32.5 & 32 & 16.0 & 21.8 & $<.001^{*}$ \\
\hline 7. Attacked someone with a weapon & 58 & 58.6 & 11 & 11.0 & 49.7 & $<.001^{*}$ \\
\hline
\end{tabular}

*Note: Bonferroni correction at $p<.05$ is $p<.007$. 
Table 7

Individual Item $t$-tests of Violence Use Intensity

\begin{tabular}{|c|c|c|c|c|c|}
\hline Variable & IY & $\mathrm{NI}$ & $t$ & $d f$ & $p$-value \\
\hline 1. Attacked someone you lived with & .616 & .370 & 3.57 & 197 & $<.001$ \\
\hline 2. Involved in a physical fight in the past 12 months* & .720 & .450 & 4.01 & 195.953 & $<.001$ \\
\hline $\begin{array}{l}\text { 3. In the previous } 12 \text { months received an injury in a } \\
\text { fight requiring medical care* }\end{array}$ & .220 & .04 & 3.91 & 141.195 & $<.001$ \\
\hline 4. Been involved in a gang fight* & .520 & .150 & 6.00 & 179.212 & $<.001$ \\
\hline 5. Carried a weapon such as a knife* & .394 & .152 & 3.96 & 179.817 & $<.001$ \\
\hline 6. Ever carried a hidden weapon & .650 & .320 & 4.92 & 198 & $<.001$ \\
\hline 7. Attacked someone with a weapon* & .586 & .110 & 8.08 & 165.746 & $<.001$ \\
\hline
\end{tabular}

*Note: Equal variance not assumed;

***Bonferroni correction at $p<.05$ is $p<.007$. 
variable being violence witnessing intensity and the dependent variable being use of violence intensity. The results of both regression analyses showed that witnessing violence significantly predicted use of violence, as can be seen in Tables 8 and 9.

\section{Table 8}

Regression Equation Predicting Extent of the Use of Violence from Extent of Witnessing of Violence ${ }^{\mathrm{a}}$

\begin{tabular}{lccc}
\hline Variable & $B$ & $\beta$ & Adjusted $R^{2}$ \\
\hline Witnessing Extent & .560 & .586 & .340 \\
\hline Note: Number of observations $=193 ;{ }^{\mathrm{a}} p \leq .001$.
\end{tabular}

Table 9

Regression Equation Predicting Intensity of the Use of Violence from Intensity of Witnessing of Violence ${ }^{a}$

\begin{tabular}{lccc}
\hline Variable & $B$ & $\beta$ & Adjusted $R^{2}$ \\
\hline Witnessing Intensity & .433 & .626 & .389 \\
\hline
\end{tabular}

Note: Number of observations $=193 ;{ }^{2} p \leq .001$.

Violence Witnessing Extent predicted Use of Violence Extent scores, $B=$ $.56, t=9.98, p<.001$. Similarly, the Violence Witnessing Intensity scores were also significant predictors of the Use of Violence Intensity scores, with $B=.43, t$ 
$=11.10, p=<.001$. Therefore, a higher level of violence witnessing was shown to be related to a higher level of violence use as expected for hypothesis 1 .

\section{Hypothesis 2: Violence Victimization}

The second hypothesis stated that the greater the exposure to violence by victimization the greater the reported use of violence by African American male youth. The scores from two instruments: (a) the Survey of Exposure to Community Violence-Violence Victimization Self Report Version (Richters, 1990) and (b) the Use of Violence Scale adapted by DuRant et al. (1994) were calculated to determine if experiencing violent victimization was significantly related to the use of violence.

Accordingly, scores from the Violence Victimization Extent Scale were calculated in two ways. Using the calculation method adopted by Fitzpatrick and Boldizar (1993), the first 9 items of the Victimization Extent Scale were dummy coded and then summed with $0=$ never and $1=$ sometimes, often or very often. (Responses to Item \#10: "Have you ever shot or shot at someone else?" were discarded because they reflected violence use as opposed to violent victimization.) The final victimization extent scores ranged from 0 to 9 . The total mean score for victimization extent was 3.92 , and the $S D=2.11$. As expected, incarcerated youth had significantly higher scores on 7 of the 9 items summed in the first scale calculations (see Table 10). This scale was found to be reliable with this sample as confirmed by a Chronbach's alpha of .69 . 
Table 10

Numbers of African American Youth Experiencing Individual

Violence Victimization Extent Items

\begin{tabular}{|c|c|c|c|c|c|c|}
\hline \multirow[b]{2}{*}{ Variable } & \multicolumn{2}{|c|}{ IY } & \multicolumn{2}{|c|}{$\mathrm{NI}$} & \multirow[b]{2}{*}{$x^{2}$} & \multirow[b]{2}{*}{$p$-value } \\
\hline & $n$ & $\%$ & $n$ & $\%$ & & \\
\hline 1. Have you ever been chased when it wasn't just for fun? & 81 & 41.1 & 60 & 30.5 & 10.3 & .001 \\
\hline 2. Have you ever been hit by family members? & 82 & 41.2 & 78 & 39.2 & .326 & .568 \\
\hline 3. Have you ever been hit by non-family members? & 86 & 43.0 & 65 & 32.5 & 11.9 & $.001^{*}$ \\
\hline 4. Have you ever been beaten or mugged? & 41 & 20.5 & 10 & 5.0 & 25.3 & $<.001^{*}$ \\
\hline 5. Have you ever been sexually assaulted? & 12 & 6.0 & 7 & 3.5 & 1.51 & .219 \\
\hline 6. Have you ever been attacked with a knife? & 47 & 23.5 & 19 & 9.5 & 17.7 & $<.001^{*}$ \\
\hline $\begin{array}{l}\text { 7. Have you ever been seriously wounded after } \\
\text { an incidence of violence? }\end{array}$ & 46 & 23.0 & 12 & 6.0 & 28.1 & $<.001^{*}$ \\
\hline 8. Have you ever been shot or shot at by someone else? & 67 & 33.5 & 28 & 14.0 & 30.5 & $<.001^{*}$ \\
\hline $\begin{array}{l}\text { 9. Has your home ever been broken into when you were } \\
\text { at home? }\end{array}$ & 23 & 11.6 & 17 & 8.5 & 1.12 & .305 \\
\hline
\end{tabular}

*Note: Bonferroni correction at $p<.05$ is $p<.006$. 
Victimization extent: Own gun/gun in household. The final two items in the Victimization Extent Scale called for categorical responses (yes, no, unknown): (11) Do you own a gun? and (12) Is there a gun in your household? These two items were calculated using chi-square statistical methods (see Tables 11 and 12) which did in fact reveal that incarcerated youth reported owning a gun significantly more frequently than non-incarcerated youth ( $78 \%$ vs. $22 \%$ respectively). However, there was no significant difference between the groups in the extent to which they reported having a gun in their household $(51.6 \%$ vs. $48.4 \%$ respectively).

As with victimization extent, for victimization intensity a sum of the 9 items of the scale resulted in frequency scores ranging from $0=$ never to $3=$ very often, and resulting in a total victimization intensity score ranging from 0 to 27 . The total mean for victimization intensity was $5.90, S D=4.27$. Of the nine items on this scale, incarcerated youth were shown to have significantly higher scores on six items (see Table 13). Furthermore, with this sample the victimization intensity scores were shown to be slightly more reliable than the witnessing extent scores with a Chronbach's alpha of .77 for intensity and of .70 for extent. 
Table 11

Victimization Extent Item \#11 -

"Do You Own a Gun?"a

\begin{tabular}{lcccc}
\hline & Yes & No & Unknown & Totals \\
\hline IY & 25 & 65 & 6 & 96 \\
$\%$ of Total & $78 \%$ & $42 \%$ & $60 \%$ & \\
NY & 7 & 92 & 1 & 100 \\
$\%$ of Total & $22 \%$ & $59 \%$ & $10 \%$ & 196 \\
Totals & 32 & 157 & 7 & \\
\hline Note: ${ }^{\mathrm{a}} \chi^{2}=14.372, d f=1, p<.001$. & & & \\
\end{tabular}

Table 12

Victimization Extent Item \#12 - "Is There a Gun in Your Household?"

\begin{tabular}{llllc}
\hline & Yes & No & Unknown & Totals \\
\hline IY & 32 & 48 & 16 & 96 \\
$\%$ of Total & $51.6 \%$ & $44 \%$ & $67.9 \%$ & \\
NY & 30 & 61 & 9 & 100 \\
$\%$ of Total & $48.4 \%$ & $56 \%$ & $32.1 \%$ & \\
Totals & 62 & 109 & 28 & 196 \\
\hline
\end{tabular}

Note: Non-significant. 
Table 13

Individual Item $t$-tests of Victimization Intensity

\begin{tabular}{|c|c|c|c|c|c|}
\hline Variable & IY & NI & $t$ & $d f$ & $p$-value \\
\hline Have you ever been chased when it wasn't just for fun* & .818 & .612 & 3.27 & 184.42 & $.001^{* *}$ \\
\hline Have you ever been hit by family members? & .820 & .788 & .568 & 197 & .570 \\
\hline Have you ever been hit by non-family members?* & .860 & .650 & 3.54 & 180.860 & .001 \\
\hline Have you ever been beaten or mugged?* & .410 & .100 & 5.35 & 163.709 & $<.001$ \\
\hline Have you ever been sexually assaulted?* & .121 & .07 & 1.23 & 185.307 & .222 \\
\hline Have you ever been attacked with a knife?* & .470 & .190 & 4.39 & 187.535 & $<.001$ \\
\hline $\begin{array}{l}\text { Have you ever been seriously wounded after an } \\
\text { incidence of violence?* }\end{array}$ & .460 & .120 & 5.69 & 170.290 & $<.001$ \\
\hline Have you ever been shot or shot at by someone else? & .670 & .280 & 5.97 & 198 & $<.001$ \\
\hline $\begin{array}{l}\text { Has your home ever been broken into when you were } \\
\text { at home?* }\end{array}$ & .230 & .172 & 1.02 & 195.084 & .307 \\
\hline
\end{tabular}

*Note: Equal variance not assumed;

**Bonferroni correction at $p<.05$ is $p<.006$. 
In order to test the second hypothesis scatterplots were examined and positive linear relationships were found between use of violence and violence victimization. Violence victimization extent scores were significant predictors of violence use, as can be seen in Table 14, where $B=.66, t=12.00, p<.001$. Similarly using Violence Victimization intensity scores as the independent variable a regression successfully predicted violence use where $B=.81, t=14.69, p<.001$ (see Table 15). Thus, as stated in hypothesis 2 , as victimization intensity and extent increased, the use of violence also increased.

Table 14

Regression Equation Predicting Extent of the Use of Violence from Extent of Violence Victimization ${ }^{\mathrm{a}}$

\begin{tabular}{cccc}
\hline Variable & $B$ & $\beta$ & Adjusted $R^{2}$ \\
\hline Violence Victimization & .657 & .658 & .430 \\
\hline Note: Number of observations $=191 \cdot{ }^{\mathrm{a} p} \mathrm{p}$ & .001 & \\
\hline
\end{tabular}

Note: Number of observations $=191 ;{ }^{a} p \leq .001$.

Table 15

Regression Equation Predicting Intensity of the Use of Violence from Intensity of Violence Victimization ${ }^{2}$

\begin{tabular}{llll}
\hline Variable & $B$ & $\beta$ & Adjusted $R^{2}$ \\
\hline Violence Victimization & .813 & .730 & .531 \\
\hline
\end{tabular}

Note: Number of observations $=191 ;{ }^{\mathrm{a}} p \leq .001$. 


\section{Hypothesis 3: Daily Urban Hassles}

The third hypothesis predicted that the greater the level of daily urban hassles experienced by African American male youth, the greater their reported use of violence. The Urban Hassles Scale (Miller, 1999) was used to assess the level of urban hassles experienced by these youth. The respondent data from this scale and the Use of Violence Scale (DuRant et al., 1994) within both the extent and intensity domains were then examined for linear relationships, which were obtained.

During the data collection, non-incarcerated respondents were asked to think back over the last 2 weeks and indicate how often specific events identified as urban hassles had happened to them. Incarcerated youth were asked to think back to before their incarceration and indicate how often urban hassle events had happened to them. The Urban Hassles Scale score was calculated by summing the scores for each of the 12 items which ranged from $0=$ never to $3=$ very often, resulting in a total Urban Hassles score ranging from 0 to 36 . The total mean score calculations for this scale show a substantial exposure to urban hassles with $M=7.77, S D=5.66$. On average the youth had some exposure to the majority of urban hassles. Following reliability calculations the overall Urban Hassles Scale was shown to be moderately reliable with a Chronbach's alpha of .76 within this sample.

Using the same statistical calculations for the Use of Violence Scale (DuRant et al., 1994), the third hypothesis was examined. Scatterplots and 
regression analysis revealed linear relationships as predicted in hypothesis 3 , between use of violence and urban hassles across both the extent and intensity domains. For hypothesis 3, Urban Hassles scores significantly predicted the extent of the use of violence as is evident in Table $16(B=.16, t=6.67$, and $p<$ $.001)$. Consistent with hypotheses 1 and 2 the intensity calculation once again yielded a more robust statistical relationship between urban hassles and the use of violence with $B=.44, t=8.57$ with a $p<.001$ (see Table 17).

Table 16

Regression Equation Predicting Extent of the Use of Violence from Urban Hassles Score ${ }^{a}$

\begin{tabular}{lccc}
\hline Variable & $B$ & $\beta$ & Adjusted $R^{2}$ \\
\hline Urban Hassles & .163 & .436 & .186 \\
\hline Note: Number of observations $=192 ;{ }^{\mathrm{a}} p \leq .001$.
\end{tabular}

Table 17

Regression Equation Predicting Intensity of the Use of Violence from Urban Hassles Score ${ }^{a}$

\begin{tabular}{lllc}
\hline Variable & $B$ & $\beta$ & Adjusted $R^{2}$ \\
\hline Urban Hassles & .444 & .528 & .275 \\
\hline
\end{tabular}

Note: Number of observations $=192 ;{ }^{2} p \leq .001$. 


\section{Hypothesis 4: Racial Socialization}

The fourth hypothesis was that the more racial socialization African American male youth received, the less they would report the use of violence. The Scale of Racial Socialization-Adolescent Version (Stevenson, 1994b) was employed to assess the level of racial socialization this sample of youth received. Calculation of racial socialization scores proceeded by reverse coding negatively worded items and then summing the scores for each of the 45 items. Items could range from $0=$ "disagree a lot" to $4=$ "agree a lot," resulting in a possible score range from 0 to 180 . The Racial Socialization Scale analysis revealed a total mean of 130.27 , a $S D$ of 14.62 , and an actual range of 77.0 to 157 . A Chronbach's alpha of .64 was obtained; this scale can be considered mildly reliable.

In order to test the fourth hypothesis scatterplots were examined for linear relationships and regression analyses were also performed with racial socialization as the independent variable and use of violence as the dependent variable (see Tables 18 and 19). The results of the statistical calculations for racial socialization and use of violence extent confirmed the hypothesis with $B=-.032, t=-3.10$, and where $p=.002$. Calculations for racial socialization intensity also confurmed the hypothesis that as racial socialization increased, use of violence decreased with results of $B=-.065, t=-2.75$, and where $p=.007$. 
Table 18

Regression Equation Predicting Extent of the Use of Violence from Racial Socialization Scale Score ${ }^{2}$

\begin{tabular}{llll}
\hline Variable & $B$ & $\beta$ & Adjusted $R^{2}$ \\
\hline Racial Socialization & -.032 & -.223 & .045 \\
\hline Note: Number of observations $=185 ;{ }^{a} p=.002$.
\end{tabular}

Table 19

Regression Equation Predicting Intensity of the Use of Violence from Racial Socialization Score ${ }^{a}$

\begin{tabular}{llll}
\hline Variable & $B$ & $\beta$ & Adjusted $R^{2}$ \\
\hline Racial Socialization & -.065 & -.199 & .034 \\
\hline Note: Number of observations $=185 ;{ }^{\mathrm{a}} p=.007$.
\end{tabular}

Hypothesis 5: Prosocial Attitudes Toward

$\underline{\text { Respect }}$

The fifth hypothesis was that the more prosocial attitudes toward respect that African American male youth had, the less they would report the use of violence. The African American Respect Scale-Male Adolescent Version was developed and used to assess this sample of youths' attitudes toward respect (Leary, 1999).

To determine scores for this 20 -item scale, because this instrument included negatively worded items, these items were reverse coded for scoring and 
calculation purposes. Since responses could range from $0=$ "strongly disagree" to $3=$ "strongly agree," possible scores therefore ranged from 0 to 60 . An item analysis was conducted to determine the combination of items with the highest internal consistency (see Table 20). All 20 items were retained as a result of the analysis. With a Chronbach's alpha of .77 the scale is moderately reliable demonstrating high internal consistency.

Table 20

African American Respect Scale-Male Adolescent Version

\begin{tabular}{|c|c|c|}
\hline $\begin{array}{l}\text { Corr } \\
\text { Total }\end{array}$ & $\begin{array}{l}\text { ected Item- } \\
\text { Correlation }\end{array}$ & $\begin{array}{l}\text { Alpha if } \\
\text { Deleted }\end{array}$ \\
\hline 1. I admire my family & .350 & .761 \\
\hline 2. People treat me well because they are afraid ${ }^{2}$ & .456 & .754 \\
\hline 3. It is difficult to get appreciation as a black $\operatorname{man}^{2}$ & .349 & .760 \\
\hline 4. The police trust and appreciate me & .323 & .762 \\
\hline 5. I listen and appreciate the guidance my parents give me & .344 & .761 \\
\hline 6. No one will respect you unless you demand it $^{\mathrm{a}}$ & .341 & .761 \\
\hline 7. African Americans are highly regarded in America & .271 & .766 \\
\hline 8. I am valued and appreciated by my teachers & .353 & .760 \\
\hline 9. I am proud of my family's achievements & .305 & .763 \\
\hline 10. A girl appreciates a young man that takes control ${ }^{2}$ & .104 & .775 \\
\hline 11. People will admire me if I have expensive things ${ }^{2}$ & .292 & .764 \\
\hline 12. Sales people are happy to assist me in department stores & .448 & .753 \\
\hline 13. My father is a good role model & .175 & .777 \\
\hline 14. I may hurt someone if they try to embarrass me in front of people ${ }^{2}$ & .410 & .755 \\
\hline 15. If someone curses at a member of my family I might hurt them a & .342 & .761 \\
\hline 16. I have a good chance of getting good jobs that I qualify for & .477 & .751 \\
\hline 17. My family admires and appreciates me & .307 & .763 \\
\hline 18. Someone can offend me by the way they look at $\mathrm{me}^{2}$ & .357 & .760 \\
\hline 19. You can get respect if you are in a gang ${ }^{2}$ & .310 & .763 \\
\hline $\begin{array}{l}\text { 20. When I am in a bank or other places of business people are helpful } \\
\text { and pleasant toward me }\end{array}$ & .408 & .756 \\
\hline
\end{tabular}


Given the reliability of the African American Respect Scale, it was determined that the data collected from this scale could indeed be used to test hypothesis 5. The results of a linear regression analysis did confirm the prediction that the more prosocial the attitudes toward respect of the African American male youth in this sample, the less use of violence they reported. This was true for both the extent and intensity calculations of the violence use scores, as can be seen in Table 21 and 22. The results of the linear regression where the independent variable was the level of prosocial attitudes toward respect and the dependent variable was use of violence extent showed a $B=-.124, t=-7.17$, with $p<$ .001 . For the independent variable of prosocial attitudes of respect with the dependent variable of use of violence intensity the regression analysis revealed $B=$ $-.28, t=-7.23$, and $p=<.001$.

Table 21

Regression Equation Predicting Extent of the Use of Violence from the African American Prosocial Respect Scale

\begin{tabular}{cccc}
\hline Variable & $B$ & $\beta$ & Adjusted $R^{2}$ \\
\hline Respect Scale & -.124 & -.467 & .214 \\
\hline
\end{tabular}

Note: Number of observations $=186 ;{ }^{2} p \leq .001$. 
Table 22

Regression Equation Predicting Intensity of the Use of Violence from the African American Prosocial Respect Scale ${ }^{2}$

\begin{tabular}{lccc}
\hline Variable & $B$ & $\beta$ & Adjusted $R^{2}$ \\
\hline Respect Scale & -.282 & -.470 & .217 \\
\hline Note: Number of observations $=186 ;{ }^{\mathrm{a}} p \leq .001$.
\end{tabular}

Additional Quantitative Analysis

A stepwise multiple regression analysis was performed using independent variables which have been determined to be reliable for these subjects.

Independent variables included: violence witnessing, violence victimization, daily urban hassles, racial socialization, and prosocial attitudes toward respect. The dependent measure for this analysis was the use of violence. The goal of this analysis was to determine which combination of variables was the strongest predictor of violence for African American male youth.

Before the analysis was undertaken, bivariate calculations were computed for two sets of variables: predictor and criterion variables in which the violence variables are calculated using the DuRant et al. (1994) procedure that yields extent scores as in Table 23 or intensity scores as in Table 24 . All of the correlation coefficients are in the expected direction, with use of violence being inversely related to prosocial variables, racial socialization and respect and the remaining 
Table 23

Bivariate Correlations of Criterion and Predictor

Variables-Extent Calculation

\begin{tabular}{|c|c|c|c|c|c|c|}
\hline Variable Name & $\begin{array}{c}\text { Total Extent } \\
\text { of Use }\end{array}$ & $\begin{array}{l}\text { Total } \\
\text { Respect }\end{array}$ & $\begin{array}{l}\text { Total Urban } \\
\text { Hassles }\end{array}$ & $\begin{array}{l}\text { Total Racial } \\
\text { Socialization }\end{array}$ & $\begin{array}{l}\text { Victimization } \\
\text { Extent }\end{array}$ & $\begin{array}{c}\text { Witnessing } \\
\text { Extent }\end{array}$ \\
\hline Total extent of use of violence & 1 & & & & & \\
\hline Total respect & $-.467^{* *}$ & 1 & & & & \\
\hline Total urban hassles & $.436^{* *}$ & $-.452 * *$ & 1 & & & \\
\hline Total racial socialization & $-.223^{* *}$ & $.233^{* *}$ & -.010 & 1 & & \\
\hline Victimization extent & $.658 * *$ & $-.467 * *$ & $.533 * *$ & $-.157 *$ & 1 & \\
\hline Witnessing extent & $.586^{* *}$ & $-.393^{* *}$ & $.531^{* *}$ & -.122 & $.593 * *$ & 1 \\
\hline
\end{tabular}




\section{Table 24}

Bivariate Correlations of Criterion and Predictor

Variables-Intensity Calculation

\begin{tabular}{|c|c|c|c|c|c|c|}
\hline Variable Name & $\begin{array}{l}\text { Total Intensity } \\
\text { of Use }\end{array}$ & $\begin{array}{l}\text { Total } \\
\text { Respect }\end{array}$ & $\begin{array}{c}\text { Total Urban } \\
\text { Hassles }\end{array}$ & $\begin{array}{l}\text { Total Racial } \\
\text { Socialization }\end{array}$ & $\begin{array}{l}\text { Victimization } \\
\text { Extent }\end{array}$ & $\begin{array}{c}\text { Witnessing } \\
\text { Extent }\end{array}$ \\
\hline Total intensity of use of violence & 1 & & & & & \\
\hline Total respect & $-.470^{* *}$ & 1 & & & & \\
\hline Total urban hassles & $.528 * *$ & $-.452 * *$ & 1 & & & \\
\hline Total racial socialization & $-.199 * *$ & $.233^{* *}$ & -.010 & 1 & & \\
\hline Victimization intensity & $.730^{* *}$ & $-.430 * *$ & $.596 * *$ & -.141 & 1 & \\
\hline Witnessing intensity & $.626^{* *}$ & $-.315^{* *}$ & $.635^{* *}$ & -.107 & $.663^{* *}$ & 1 \\
\hline
\end{tabular}


variables directly related to violence use. Consistent with previous results, racial socialization was negatively and weakly correlated with violence victimization and violence witnessing. As expected the respect scale showed a strong direct relationship with racial socialization. The three stress related predictors: violence witnessing, violence victimization and urban hassles had a significant inverse relationship with the respect scale. In Table 24 exactly the same patterns of correlations can be seen, as in Table 23.

The three stress variables of violence witnessing, violence victimization and urban hassles were all shown to be significant predictors of the criterion variable, use of violence. The two sociocultural variables of racial socialization and prosocial respect were also highly significant predictors of the use of violence. Therefore multiple regression analysis was used to determine whether prediction could be improved by using a combination of these variables. Since the interrelationship amongst these variables had not been shown in prior research, a stepwise multiple regression method was chosen. The strongest predictor of use of violence was victimization extent as can be seen in Table 25; alone it accounted for $43.3 \%$ of the total variance in use of violence. In the second step of the regression witnessing was added to the equation which increased the explained variance to $49.2 \%$. The third and final step added respect to the regression accounting for a total of $51.2 \%$ of the variance of the extent of the use of violence. Variables excluded from the final regression equation were racial socialization and urban 
hassles which failed to significantly increase the prediction of the criterion variable of extent of use of violence.

\section{Table 25}

Stepwise Linear Regression Predicting the Extent of the Use of Violence for African American Male Youth

\begin{tabular}{|c|c|c|c|c|}
\hline Variable & $B$ & $S E B$ & Beta & $p$-value \\
\hline \multicolumn{5}{|l|}{ Step 1} \\
\hline Victimization Extent & .657 & .057 & .658 & $<.001$ \\
\hline \multicolumn{5}{|l|}{ Step 2} \\
\hline Victimization Extent & .478 & .067 & .479 & $<.001$ \\
\hline Witnessing Extent & .288 & .064 & .302 & $<.001$ \\
\hline \multicolumn{5}{|l|}{ Step 3} \\
\hline Victimization Extent & .419 & .069 & .419 & $<.001$ \\
\hline Witnessing Extent & .260 & .064 & .273 & $<.001$ \\
\hline Total Respect & -.044 & .016 & -.164 & .008 \\
\hline
\end{tabular}

Note: $R^{2}=.433$ for Step $1(p<.001)$; Change $R^{2}=.059$ for Step $2(p<$ $.001)$; Change $R^{2}=.020$ for Step $3(p<.001)$; Total $R^{2}=.512 ; n=178$.

The same pattern was found for predicting the strength of variance for intensity of the use of violence by using the same predictor variables in a separate stepwise multiple regression seen in Table 26. An even stronger combination of predictors was revealed with a total of $59.6 \%$ of the variance explained for use of violence intensity. 
Table 26

Stepwise Linear Regression Predicting the Intensity of the Use of Violence for African American Male Youth

\begin{tabular}{|c|c|c|c|c|}
\hline Variable & B & SE B & Beta & $p$-value \\
\hline \multicolumn{5}{|c|}{ Step 1} \\
\hline Victimization intensity & .813 & .057 & .730 & .001 \\
\hline \multicolumn{5}{|c|}{ Step 2} \\
\hline Victimization intensity & .626 & .074 & .562 & $<.001$ \\
\hline Witnessing intensity & .175 & .046 & .253 & $<.001$ \\
\hline \multicolumn{5}{|c|}{ Step 3} \\
\hline Victimization intensity & .546 & .075 & .490 & $<.001$ \\
\hline Witnessing intensity & .168 & .045 & .243 & $<.001$ \\
\hline Total Respect & -.110 & .032 & -.183 & .001 \\
\hline
\end{tabular}

Qualitative Data Analysis

In addition to quantitative questions the instruments included two open ended qualitative questions: "If you and your friends have felt disrespect at some time in your life why do you think it happened?" and, "Why do you think people like you are disrespected?" Themes were identified resulting from the two questions related to sociocultural factors.

There were three independent readers of the open-ended questions that helped to determine the coding of responses. Thirteen major coding categories 
were developed after a preliminary analysis, and a second analysis was used to develop 6 subcategories of coding. Because of the limited amount of data collected, the answers were transcribed from the written responses and through electronic word processing and coded by hand.

The coding categories were related to: (1) race (ethnicity and culture); (2) racism (police profiling, stereotyping, and prejudice); (3) behavior (youths own actions); (4) dress (clothing and jewelry); (5) jealousy (physical attractiveness, attention from females, talents or skills); and gangs (involvement with gang activity or being perceived as belonging to a gang or engaging in gang activity).

The largest number of responses for the two questions identified race and racism as the source of the disrespect thus, the reported results are focused primarily on the responses related to these areas. These are considered separately for IY and NI whose responses were only separated by group since these responses could not be connected to any one group.

\section{Past Disrespect}

Incarcerated group. A total of 94 of the incarcerated subjects answered the question: "If you and your friends have felt disrespect at some time in your life why do you think it happened?" Of the 94 responses, 35 identified their race or being black as the reason why they were disrespected. Nineteen identified racism as a cause, 8 attributed the disrespect directly to their behavior; 11 stated that the way they were dressed prompted the disrespect; 11 suggested that it was jealousy, 
and 10 said that gang involvement or perceived gang involvement was the cause. Youth frequently associated the disrespect they had experienced directly with racism. One youngster stated: "Yes, I've felt disrespected before, a lot of white people think that young blacks are bad." Several youth stated that they had been disrespected by law enforcement officers specifically because they are disliked by the police in general:

At the [local mall] . . ., me and my friends often feel disrespected when security guards would follow us and tell us to split up or leave. I think we were harassed because they stereotyped us as "gangsters" because we were of color.

Non-incarcerated group. A total of 95 non-incarcerated subjects answered the question: "If you and your friends have felt disrespect at some time in your life why do you think it happened?" Of the 95 responses, 43 identified their race or being black as the reason why they were disrespected. Twenty-five identified racism as a cause, 16 attributed the disrespect directly to their behavior; 7 stated that the way they were dressed prompted the disrespect; 10 suggested that it was jealousy, and 4 said that gang involvement or perceived gang involvement was the cause. One youth stated that he thought he and his friends were disrespected because "We were young black males living in a white man's world. They made harsh generalizations that weren't true."

Several youth identified a host of culturally specific attributes as contributing to their being disrespected: An example is the following "Because they looked at us different. They looked at the way we dressed, the way we 
talked, the way we walked, and they thought it wasn't right to act that way." Another youth stated:

I think that it happened because of the fact that a lot of white people think African boys look suspect. I think no matter how we present ourselves we are all looked at as trouble makers.

\section{General Disrespect}

Incarcerated group. A total of 96 non-incarcerated subjects answered the question: "Why do you think people like you are disrespected?" Of the 96 responses, 49 identified their race or being black as the reason why they felt that people like them were disrespected. Twelve identified racism as a cause, 12 attributed the disrespect directly to their behavior; 10 stated that the way they were dressed prompted the disrespect; 18 suggested that it was jealousy, and 5 said that gang involvement or perceived gang involvement was the cause.

Again, youth answered similarly with comments suggesting race, or skin color as a major cause of their being disrespected. One young man included his cultural habits and behaviors along with being black as the cause:

Cause I'm black, Cause I like rap, Cause I eat soul food, Cause my hair is nappy, Cause of where I come from. Cause I date all races, Cause I talk different, Cause other races don't understand what it is like to be black.

Another young man specifically commented on skin color. He stated: "I get disrespected cuz of my color. There's too many people who think they are better than us just cuz they got white skin." Several youth suggested a larger societal issue of racism as the reason for their being disrespected as reflected in the 
following comments: "Because we are African Americans and society has put out a stereotype towards us," "Because it always been that way, and it will always be because a lot of white people think they are better than everybody," and "Because we are black in a white man's America."

There was an uncharacteristic response to this question by one youth that deserves comment. The young man's response to the question of why he felt people like himself were disrespected was "because we have a lot of hate and anger and are vulnerable when it comes to personal comments." While the "we" in this comment was not specified as being "we" as blacks or youth or males, it raises an interesting question as to the youth's perceptions about how his emotional and psychological state influenced how others perceive him. The more important question about his response is why he feels people like him have a lot of hate and anger. This is particularly interesting in light of issues of how trauma impacts behavior.

Non-incarcerated group. A total of 90 non-incarcerated subjects answered the question: "Why do you think people like you are disrespected?" Of the 90 responses, 38 identified their race or being black as the reason why they felt that people like them were disrespected. Twenty-six identified racism as a cause, 8 attributed the disrespect directly to their behavior; 3 stated that the way they were dressed prompted the disrespect; 14 suggested that it was jealousy and 1 said that gang involvement or perceived gang involvement was the cause. 
Predictably, the comments were consistent with the others with respect to

race and racism; however, there was a distinct difference in the level of clarity and articulation. It would be expected that the non-incarcerated youth would have higher writing as well as verbal skills as demonstrated by the following responses:

People like me are generally treated with a lack of respect because blacks are categorized as loud and violent when that is not always true. Yes, there are loud and violent blacks, but it is the same with all races. White, Mexican, whatever. Every person is different and their qualities should not be linked to their race.

Several youth identified racism or racist practices as a specific cause of disrespect:

We are disrespected because we are not given the opportunity to show what we can actually do. Our potential can not be presented because we are not given the same chances.

Just cuz they're black. I mean for example, there's a white boy in my class. He's my friend but we help each other on class work and we basically get the same answers but for some reason he gets an A and I get a B with a minus, like I said, cuz I'm black.

Several youth identified societal fear as the root cause of the disrespect:

Because there are still people out there that haven't realized that there is no longer just one dominant race anymore. Blacks and as well as other races are on the rise in this country and they don't like it,

They don't know what we might do next. They think we're dangerous and hostile. They know that within ourselves we possess a lot of power and they're scared and intimidated by us.

\section{Summary of Qualitative Results}

In comparing the incarcerated and non-incarcerated group responses, many similarities were found. Both groups heavily endorsed race as a cause of why they 
or their group were disrespected. While non-incarcerated youth more frequently cited racism as the cause, both groups reported police profiling, stereotyping and prejudice as factors associated with racial discrimination. The groups had slightly differing responses with respect to behavior and jealousy. The incarcerated group attributed more of the disrespect they experienced to jealousy than did the nonincarcerated youth, and the non-incarcerated youth attributed more of the disrespect to their own or other's individual behaviors than did the incarcerated group. 


\section{CHAPTER V}

\section{DISCUSSION AND CONCLUSION}

This study evaluated five hypotheses addressing the prediction of the use of violent behavior by African American male youth. These first three hypotheses addressed stressors experienced by African Americans: violence witnessing, violence victimization, and daily urban hassles. First it was hypothesized that the greater the exposure to violence by witnessing the greater the reported use of violence by African American male youth. The second hypothesis predicted that the greater the exposure to violence by victimization the greater the reported use of violence by African American male youth. Third, it was predicted that the greater the level of daily urban hassles experienced by African American male youth, the greater their reported use of violence. The fourth and fifth hypotheses addressed the sociocultural characteristics of racial socialization. The fourth hypothesis predicted that the more racial socialization African American male youth received, the less they would report the use of violence. The fifth and final prediction was that the more prosocial attitudes toward respect that African American male youth had, the less they would report the use of violence. All five hypotheses were supported by the data of this dissertation. 
Additionally, using a stepwise multiple regression procedure, a large percentage of the variance of the use of violence was explained. The data from the equation predicting the extent of violence use suggest that exposure to trauma in the form of violence victimization, and violence witnessing accounted for $49.2 \%$ of the total variance in use of violence. Adding the sociocultural variable of respect accounted for a total of $51 \%$ of the total variance in use of violence. These results clearly identify trauma exposure in the form of environmental stressors as a significant predictor of violence. In addition, the sociocultural variable of respect transmitted by way of key relationships is also essential in predicting violence among African American male youth.

The results obtained in this study present a challenge to many current explanations about the causes of African American male youth violence. One of these explanations proposes that violence among African American male youth is due to a propensity for conforming to cultural values that are reflective of lower class traditions and social disorganization. Another explanation suggests that poverty leads to criminal behavior and social chaos. Those who hold the latter belief identify continual unemployment, female-headed households, juvenile pregnancies, academic deficits, welfare dependency, and drug abuse as the major contributors to violent and illicit activities (Oliver, 1994). Still others conclude that poverty and discriminatory treatment discourage black male youth from conforming to conventional values and conduct, and that the frustration of not being able to achieve success as measured by society, leads to anger which results 
in unlawful and violent behavior (Cole, 1999). Traditional explanations for the causes of violence among African American male youth have even suggested that genetic and biological factors are the possible source (Miczek, Mirsky, Carey, DeBold, \& Raine, 1994).

Mattaini and Thyer (1996) provided another lens through which to look at youth violence, the social learning perspective. They argued that the violence may be a learned response to a traumatic event, or chronic social and economic deprivation; it may be used to achieve recognition, acceptance, or respect. DuRant, Cadenhead, Pendergrast, Slavens, and Linden (1994) proposed that exposure to violence increases the probability that black youth will engage in violence. The data from this research illustrate the importance of combining the social learning theory with a trauma perspective to assess the dimensions and factors that accompany or predict the use of violence by African American male youth. The data also illustrate the strength of the relationship between key social psychological and environmental stressors experienced by African American male youth, and their use of violence.

Violence, Stress, and Sociocultural Factors

Perceptions of disrespect, extent of racial socialization, extent of urban hassles, violence witnessing, and violence victimization were established as predictors of the use of violence by African American male youth. 
In this study more violent youth were more likely to be victims of crime, to have witnessed episodes of crime, and reported feeling disrespected by people who typically present the socializing institutions for African American youth. These youth are using a form of thinking and rules of conduct that function as adaptive survival beliefs. What is ironic is that these youth seemingly rely on their experiences as witnesses of crime and what they have experienced as victims of crimes as a means to relate and survive in urban environments. They depend on these codes of conduct as protective beliefs to safeguard against feeling disrespected, given the fact that many of these youth report not feeling respected by their families, friends or society. In one youth's case he described the hypersensitivity that he as a criminal offender felt about criticism. Typically personal attacks are ignored, but African American youth who are violent do not feel strong linkages to their racial heritage, do not feel respected by significant others, and may not be able to shrug off such attacks. Perhaps these violent youth cannot ignore personally felt criticism or experiences of disrespect because of their anger and frustration of not being valued by specific and general others.

Demographic analysis also revealed that the presence of mother or of father in the home are key factors to consider in the assessment and treatment of African American male youth violence. These data suggest the importance for at risk, incarcerated youth of not having key adults in their lives. Compared to the nonincarcerated youth, incarcerated youth in this study were more likely to not have their mothers living in the home. Half of the respondents in both groups did not 
live with their fathers either. Additionally, compared to the non-incarcerated youth, incarcerated youth were less likely to have both father and mother living in their home.

These results raise the question, of whether the lack of mother and/or father availability for a number of youth resulted in their use of other reference points such as the code of behaviors in the streets, the standards of their peers, or their own personal definitions of tolerance versus intolerance as the bases to determine ways to handle conflict leading to violence. In a study of urban African American male youth, Paschall, Ennett, and Flewelling (1996) shared the following:

Some scholars believe that single-parenthood is a major contributor to the high incidence of violent behavior among African American youths and young adults Parallel trends of increasing rates of single parenthood and violent behavior by African American youths seem to support this assumption. (p. 3)

These authors further stated that during 1980 and 1992 as the number of single parents increased, assault and murder also increased.

\section{Future Research}

As this study indicates more pilot demonstration studies are needed in this area and should be supported by policy initiatives. These studies should be directed to test the effectiveness of a change and treatment approach that deals with exposure to violence and is based on relationships for African American violent male youth. This research should track their treatment outcomes, experiences, and quality of life. Data from such studies would test the relative effectiveness of a 
program that views violent youth as a casualty of traumatizing conditions who are in need of intervention, versus conventional approaches viewing youth as perpetrators and responsible citizens who need to be penalized and imprisoned for their actions regardless of the circumstances (real or perceived).

Hypersensitivity was one of the characteristics observed by trauma survivors as reported by Danieli (1998). Future study in this area needs to investigate the source and nature of hypersensitivity particularly to issues of disrespect, as a trigger for African American male youth violence. In this study violent youth had a higher level of hypersensitivity compared to the non-violent youth. Such research may lead to a better understanding of the functions of hypersensitivity as a safeguard to protect youth from repeated emotional injury or other purposes.

Future research may also investigate whether the response of violent African American youth to disrespect is specific only to male youth or whether black females are also affected in the same way. More studies are also needed to answer the following questions: Are black male youth more emotionally and psychologically vulnerable than other youth of color or white youth, to issues of disrespect? If so, why? What sociocultural factors come into play that influence this vulnerability?

Additionally, further research is needed to investigate how the absence of the mother in the home impacts African American male youth violence. The lack 
of fathers living in the home has long been a major focus of research on African American youth violence Bennett and Fraser (2000) explained:

Although the increase in aggravated assault and murder are unlikely to be due to any single factor, burgeoning rates of single parenthood and "father absence" are oft heard as explanations for interpersonal violence among young African Americans. In a study of 171 U.S. cities, Sampson (1987) found that rates of offending by African American juveniles were strongly influenced by variations in family structure. The disruption of African American families was found to have the largest effect on robbery and homicide . . . Sampson (1987) also found that household structure was highly correlated with the rates of violence among African American youths. (p. 96)

Further, these authors argued that more recent studies do not confirm the earlier analyses; on the contrary; the newer studies suggest much broader implications as they relate to family constellations:

In a study of 254 urban African American male adolescents across five family constellations (single mother, stepparent, biological parents, mother with extended family, and extended family only), Zimmerman, Salem and Maton (1995) concluded that father absence was not a significant predictor of delinquent behavior ... Zimmerman et al (1995) observed that single parents (mothers) appeared to compensate for father absence by cultivating auxiliary parental support. In addition, they observed that many African American youths actually continued to receive support from their fathers, even though they were outside the home. (p. 96)

The results of the data from this dissertation point squarely to the importance of the mother's presence and availability in the home as a potential protective factor for preventing violence among black male adolescents.

The data also provide beginning evidence for examining planning policy changes for juvenile justice programs. The data demonstrate that witnessing violence, experiencing violence and feeling disrespected by others are key factors 
related to the use of violence. Practitioners may assess these factors, and plan treatment around trauma relief rather than the current response of punishment and incarceration for displays of violent behavior. The results of this study suggest that we need to pay attention to the display of violent behavior as unworkable coping reactions that these youth use as a typical response to daily events. Such treatment approaches need to be the focus of study. Thus, relationship based sociocultural factors, such as family composition, hypersensitivity associated with real or perceived disrespect along with stressors related to environmental traumas should become a major focus of research.

\section{Implications for Practice}

The research highlights the importance of the respect scale in helping to explain part of the variance that distinguishes African American male youth who used a higher level of violence, from those less violent. In this research, youth who felt respected were also likely to report more extensive racial socialization. On the other hand violent youth who had witnessed violence, experienced violence victimization and those accustomed to urban hassles were less likely to feel respected by key significant others or society at large. These data suggest that these trauma experiences of witnessing and victimization from violence are accompanied by negative perceptions and feelings of not being respected by family, peers, recognized authority and institutions, and society as a whole. 
Many of these youths' informal and formal support systems characterize a climate of despair, non-support, and having to depend on oneself to survive, cope and adapt. These data may be useful for practitioners trying to gain an understanding of the level of social and psychological stress that accompany the environmental stresses of growing up with urban hassles, limited social and family supports, and other key resources.

Practitioners need to know the role that violence played in the family's traditions, customs, and problem solving practices, according to the sociocultural perspective. In this context, the practitioner working with a violent African American youth needs to know the answers to the following questions. How did he learn the value of aggression and violence as a means to cope or problem solve? What are the consequences of not keeping face in the family as a respected and contributing member?

For practitioners to more effectively work in the African American community it would behoove them to understand what conditions lend themselves to peaceful and reasonable resolution of conflicts within that community. Knowing this, practitioners can serve as teachers and guides for those they serve.

\section{Policy Implications}

The results of this dissertation provide beginning evidence for examining planning policy changes for juvenile justice programs. Future policies may need to 
reassess the role of criminal justice in managing African American male youth violence. Diversion programs for juvenile offenders specifically designed to address the sociocultural issues of respect, may potentially provide the tools for building resilience and positive redirection for violent black male youth.

Policies need to be put into effect that serve to reduce the stressors that put African American male youth at higher risk for violence such as urban hassles associated with deteriorating neighborhoods that are unsafe and demoralizing. Such policies may include innovative housing developments that assist African American families to buy homes.

Another policy implication would be the support of programs that are based on culturally sensitive models of helping; thereby working to identify African American male youth who are at risk for becoming violent based upon their family composition, together with their exposure to violence, and hypersensitivity to issues of respect. An essential feature of this effort would be to establish programs that safeguard the dignity of the youth and their families and focus upon strengthening their existing relationships. Lastly, there is a growing need for policies geared toward support of training social workers to work directly with black youth who have been violent and to provide the youth with tools on how to articulate their frustrations and anger without becoming violent or feeling humiliated. 


\section{Unexpected Findings}

When the statement "The police trust and appreciate me" was read aloud from the African American Respect Scale, the result was spontaneous laughter from the youth being surveyed. This was a consistent reaction from all of the young men surveyed, both incarcerated and non-incarcerated. This response may indicate the lack of respect that these African American male youth feel the police have for them. Responses from both groups to open-ended qualitative questions about why they feel disrespected yielded numerous accounts of police profiling and harassment. Thus, these youth expressed the futility of attempts to ever gain the respect of law enforcement authorities. This is particularly alarming when considering the fact that recent urban civil disorders inclusive of violence and rioting have occurred as a direct result of incidents involving police officers and African American males. Youth surveyed repeatedly indicated how their interactions with police officers resulted in their feeling demoralized and emasculated. Youth who feel that they have been publicly humiliated and their masculinity or manhood challenged, may believe that retaliation in the form of violence is warranted. Ward (1995) explained:

Adolescents caught up in struggles of wounded pride and vengeance seek justice for themselves, yet they fail to grasp the larger significance of the need for justice for all. While a narrow perspective on adolescent violence sees it as arising merely out of interpersonal conflict, the broader picture reveals a sociopolitical backdrop in which moral codes of justice and equity are frequently violated, as in the Rodney King beating and subsequent trials. (p. 180) 
Additionally, incarcerated youths' families tended to have fewer material resources like owning a home or car as indicated by the demographic characteristics. Material resources may also have an impact on overall selfperceptions, particularly a sense of masculinity. American values of success place extreme importance on achieving academic, financial, and material prestige. African American young males, as well as males in general, often define themselves and their masculinity based upon their ability to acquire and maintain control of material goods.

White (1997) elaborated on the significance of masculinity and its link to aggressive behavior:

The expression of hegemonic masculinity thus varies according to class and cultural factors, and an individual's acceptance or rejection of its main propositions. The maintenance of this notion of manhood, however, depends not only on the idea of what it is to be a man, but on the material resources to do so. Opportunity, choice and group affinity all have an impact on how individuals construct or attempt to construct a masculine identity for themselves. And it is here, at the level of the societal resources and opportunities, that we begin to see a strong link between health issues and issues of masculinity. (p. 37)

Many of the incarcerated youth upon introduction to this writer presented themselves as "hard core" and defiant. However, by the time they had completed their survey booklets their harsh bravado disappeared and a surprisingly sensitive and docile and frequently warm side of them was observed. While this writer posed no physical threat to the young men, it became obvious that they still felt a need to protect themselves from any possible humiliation or embarrassment that 
could be brought upon them from their peers as a result of this interaction.

Additionally, when incarcerated subjects answered another survey question on the African American Respect Scale which stated: "I may hurt someone if they try to embarrass me in front of people," there was a marked difference in their affect and nonverbal response compared to non-incarcerated youth. The most striking observation was that on numerous occasions of surveying incarcerated youth, they would all respond simultaneously to this question with an affirmative head nod or a chuckle as if they believed that hurting someone that embarrassed them in front others was not only the obvious answer, but was also considered completely appropriate. There was a similar response to another statement on the same scale, "if someone curses at a member of my family I might hurt them."

Again, the incarcerated and many of the non-incarcerated youth spontaneously demonstrated their approval. These and numerous other responses suggested that there was a level of acceptance among the incarcerated and some non-incarcerated youth about protecting themselves against the slightest embarrassment or humiliation even to the extent that violence would be used.

\section{Limitations of the Study}

The first limitation of this study involves the sample. One of the sample groups under study was a group of incarcerated African American male youth who were asked to respond to questions regarding behaviors they did not have a full opportunity to engage in because of their confinement in a correctional facility. 
Secondly, the study may not be generalized to other urban populations of African American male youth, given the unique demographic characteristics and experiences of the small numbers of African Americans that live in Oregon. Another limitation is that one of the scales that was used in this study was new and had not been psychometrically tested or analyzed prior to its use in this study (Leary, 1999). While each question was read aloud to account for differential reading ability, certain words like "highly regarded" were not understood by some of the subjects and thus may have limited the accuracy of reporting. The racial socialization instrument had several questions that were perceived by the youth as redundant which mildly frustrated several of them. The instrument was also quite lengthy (45) items and may have tired some of the subjects who in turn may not have given full attention to answering each of the items. Another limitation was that the study relied exclusively on self-report data. Lastly, some of the other scales being used in this study have moderate reliability scores.

\section{Conclusion}

This research tells us about the importance of respect, witnessing violence and victimization of violence as predictors of African American male youth violence. These findings provide an empirical foundation that can be used for planning the prevention, interventions, assessment models and treatment of African American youth. It also serves as an impetus to future study of the correlates, consequences and predictors of African American male youth violence. This study 
was only the initial test of the studied variables. More research is needed to address the use of trauma perspectives and resiliency research as conceptual frameworks and as alternatives to the current criminal justice retribution response.

Through the combined lenses of trauma and resiliency we are able to study the pathways youth use from experiencing at risk situations and pain, to coping response (workable or non-workable), to finding better helping responses. These youth, and those who provide them with services, need to know what this research tell us about the culture of victimization and challenges to resiliency. The fact that more than half of the research subjects in both groups lived without the presence of a father and comparatively speaking, a large number of incarcerated youth did not have their mothers present in the home, tells us about the challenges these youth encounter as potential social and psychological stressors. These young men are without the key relationships that provide social support, affection, and nurturance that are available to most youth. 


\section{REFERENCES}

American Psychiatric Association. (1994). Diagnostic and statistical manual of mental disorders (4th ed.). Washington, DC: Author.

American Psychiatric Association. (1996). Is youth violence just another fact of life? Some kids resilient; some kids at risk. Clarifying the debate: Psychology examines the issues. Washington, DC: Author.

Anderson, E. (1999). Code of the street: Decency, violence, and the moral life of the inner city. New York: W. W. Norton and Company.

Asante, M. K., \& Asante, K. W. (1985). African culture: The rhythms of unity. Westport, CT: Greenwood Press.

Bandura, A. (1969). Principles of behavior modification. New York: Holt, Rinehart, and Winston, Inc.

Bandura, A. (1997). Self efficacy: The exercise of control. New York: W. H. Freemen and Company.

Bell, C. C. (1997, June). Community violence: Causes, prevention and intervention. Paper presented at the annual conference of the Research Training Center on Family Support and Children's Mental Health, Portland, OR.

Bell, C. C., \& Jenkins, J. E. (1991). Traumatic stress and children. Journal of Health Care for the Poor and Underserved, 2(1), 175-188

Bell, C. C., \& Jenkins, J. E. (1993). Community violence and children on Chicago's southside. Psychiatry, 56(2), 46-54.

Benjamin, M. (1995). Child and adolescent service system program initiative monograph. Washington, DC: Georgetown University Child Development Center, CASSP Technical Assistance Center.

Bennett, D. M., \& Fraser, M. W. (2000). Urban violence among African American males: Integrating family, neighborhood, and peer perspectives. Journal of Sociology and Social Welfare, 27(3), 93-117. 
Branscom, M. (1998, November 1). DNA test finds evidence that Thomas Jefferson and slave had a child. The New York Times National, pp. 20.

Briggs, H. E., Miller, D. B., Sayles, R., Tovar, D. D., \& Dozier, C. D. (1997). Correlates of substance abuse among youth: A note for professionals, service providers and families. Community Alternatives: International Journal of Family Care, 9(2), 109-142.

Brown, D. L. (1993, November 1). Getting ready to die young: Children in violent D. C. neighborhoods plan their own funerals. The Washington Post, pp. A1, A13.

Centers for Disease Control. (1999). 1999 Youth risk behavior survey. CDC Chronic Disease Adolescent Health. [On-line], xx. Available: http://www.cdc.gov/nccdphp/dash/yrbs/survey99.htm

Chestang, L. W. (1972). Character development in a hostile environment. Unpublished manuscript, University of Chicago.

Cole, D. (1999). No equal justice: Race and class in the American criminal justice system. New York: The New Press.

Comer, J. P. (1980). The black family: An adaptive perspective. Unpublished manuscript, New Haven, CT: Yale University.

Danieli, Y. (1998). International handbook of multigenerational legacies of trauma. New York: Plenum Press.

Davis-Russel, E. (1990). Ethno-cultural mental health: Staff seminar. Paper presented at Pacific University Fall Colloquium, Forest Grove, OR.

DuRant, R. H., Cadenhead, C., Pendergrast, R. A., Slavens, G., \& Linden, C. W. (1994). Factors associated with the use of violence among urban black adolescents. American Journal of Public Health, 84(4), 612.

Dwyer, K. (1994). Testimony on preventing school violence and effective methods for improving school safety, Subcommittee on Elementary, Secondary, and Vocational Education: U.S. House of Representatives. Silver Springs, MD: National Association of School Psychologists.

Face to face with slavery's victims. (1997). National Geographic, 192(4), 75. 
Fitzpatrick, K. M., \& Boldizar, J. P. (1993). Prevalence and consequences of Exposure to violence among African-American youth. American Academy of Child and Adolescent Psychiatry, 32(2), 424-430.

Froelhke, R. (1991). National report. Atlanta, GA: Center For Disease Control.

Gatto, J. T. (1992). Dumbing us down. Philadelphia, PA: New Society.

Genovese, E. D. (1976). Roll jordan roll the world the slaves made. New York: Vintage Books.

Grier, W. H., \& Cobbs, P. M. (1969). Black rage. New York: Bantam Books.

Hacker, A. (1992). Two nations: Black and white, separate, hostile, unequal. New York: Macmillan Publishing Company.

Hampton, R. L., \& Gelles, R. J. (1994). Violence towards black women in a nationally representative sample of black families. Journal of Comparative Family Studies, 24(1), 101-119.

Harer, M. D., \& Steffenmeier, D. (1992). The differing effects of economic inequality on black and white rates of violence. Social Forces, 70(4), 10351054.

Huizinga, D., Esbensen, F., \& Weiher A. (1991). Are there multiple paths to delinquency. Journal of Criminal Law and Criminology, 82, 83-119.

Kett, J. F. (1977). Rites of passage. New York: Basic Books Inc.

Leary, J. D. (1999, January). African American Respect Scale-Male Adolescent Version. Unpublished scale. Portland, OR: Portland State University.

Lidz, T. (1963). The family and human adaptation. New York: International Universities Press, Inc.

Long, R. A. (1985). Black Americana. London: Multimedia Publications.

Longres, J. F. (1995). Human behavior in the social environment (2nd ed.). Itasca, IL: F. E. Peacock.

Mattaini, M. A., \& Thyer, B. A. (1996). Finding solutions to social problems: Behavioral strategies for change. Washington, DC: American Psychological Association. 
Mattaini, M. A., Twyman, J. S., Chin, W., \& Lee, K. N. (1996). Youth violence. In M. A. Mattaini \& B. A. Thyer (Eds.), Finding solutions to social problems: Behavioral strategies for change (pp. 75-112). Washington, DC: American Psychological Association.

Mauer, M., \& Huling, T. (1995). Young black Americans and the justice system: Five years later. Washington, DC: The Sentencing Project.

Mazrui, A. A. (1986). The African: A triple heritage. Boston: Little, Brown and Company.

Mbiti, J. (1970). African religions and philosophy. New York: Doubleday.

McKinney, M. H. (1994, March). Problems facing young black men. Testimony by Marvin H. McKinney Program Officer, Charles Stewart Mott Foundation Senate Committee on Banking, Housing and Urban Affairs.

McMurray, E. J. (1990). The state of black America: National Urban League Report. Washington, DC: Library of Congress.

Miczek, K. A., Mirsky, A. F., Carey, R., DeBold, J. \& Raine, A. (1994). An overview of biological influences on violent behavior. In A. J. Reiss, Jr., K. A. Miczek, \& J. A. Roth (Eds.), Understanding and preventing violence: Vol. 2. Biobehavioral influences (pp. 1-20). Washington, DC: National Academy Press.

Miller, D. B. (1999). Urban hassles scale. Unpublished manuscript, Case Western Reserve University, Mandel School of Applied Social Sciences, Cleveland.

Miller, D. B., \& MacIntosh, R. (1999). Promoting resilience in urban African American adolescents: Racial socialization and identity as protective factors. Social Work Research, 23(3), 159-169.

Miller, P. H. (1993). Theories of human development (3rd ed.). New York: Freeman and Company.

Monahan, J. (1981). Predicting violent behavior: An assessment of clinical technique (14). Beverly Hills, CA: Sage Library of Social Research.

Morris, T. (1996). Southern slavery and the law, 1619-1860. Chapel Hill, NC: The University of North Carolina Press. 
National Institute of Mental Health. (1990). Screening survey of exposure to violence: Self report version. Rockville, MD: Author.

Nichols, E. J. (1976). Introduction to the axiological model. Paper presented to the World Psychiatric Association and the Nigerian Association of Psychiatrists. University of Ibadan, Nigeria.

Ogbu, J. U. (1990). Racial stratification and education. In G. E. Thomas (Ed.), U.S. race relations in the 1980's and 1990's: Challenges and alternatives (pp. 3-29). New York: Hemisphere Publishing Company.

Oliver, W. (1994). The violent social world of black men. New York: Lexington Books.

Paschall, M. J. Ennett, S. T., \& Flewelling, R. L. (1996). Relationships among family characteristics and violent behaviors by black and while male adolescents. Journal of Youth and Adolescence, 25(2), 177-197.

Patterson, G. R. (1995). Families: Applications of social learning to family life. Champaign, IL: Research Press.

Peterson, M. (1975). The portable Thomas Jefferson: Notes on the state of Virginia, 1781. New York: Viking Press.

Pinderhughes, E. (1989). Understanding race, ethnicity, and power. New York: The Free Press.

Prothrow-Stith, D. (1994). Building violence prevention into the classroom: A physician-administrator applies a public health model to schools. The School Administrator, 51(4), 8-12.

Reiss, A. J., \& Roth, J. A. (Eds.). (1993). Understanding and preventing violence. Washington, DC: National Academy Press.

Richters, J. E. (1990). Screening survey of exposure to community violence: Self report version. (Available from National Institute of Mental Health, 5600 Fishers Lane, Room 18C-17, Rockville, MD 20857).

Schiraldi, V., Kuyper S., \& Hewitt, S. (1996). Young African Americans and the criminal justice system in California: Five years later. San Francisco: Center for Juvenile and Criminal Justice. 
Stevenson, H. C. (1994a). Racial socialization in African American families: The art of balancing intolerance and survival. The Family Journal: Counseling Therapy for Couples and Families, 2(3), 190-198.

Stevenson, H. C. (1994b). Relationship of adolescent perceptions of racial socialization to racial identity. Journal of Black Psychology, 21 (1), 49-70.

Walker, D. (1995). Violence in the schools: How to build a prevention program from the ground up. Oregon School Study Council, 38(5), 1-58.

Ward, J. V. (1995). Cultivating a morality of care in African American adolescents: A culture-based model of violence. Harvard Educational Review, 56(2), 175-188.

White, R. (1997). Young men, violence and social health. Youth Studies, 16(1), $31-44$.

Woodman, L. (1973). Perspectives on self awareness: Essays on human problems. Columbus, $\mathrm{OH}$ : Charles E. Merrill. 
APPENDIX A

PARTICIPANT DEMOGRAPHICS 
The Survey of African American Male Youth Experience and Behavior - Instruments

\section{Part A: Demographic Questions (NIY)}

Directions: Please indicate the correct answer to the following questions by either circling the answer or filling in the box next to the answer of your choice.

1. What is your age? Please circle one of the following: $\begin{array}{lllll}14 & 15 & 16 & 17 & 18\end{array}$

2. Are you currently attending a school program? Yes $\square$ No

3. What is the highest grade in school that you have completed? Please circle one of the following:

$$
7^{\text {th }} 8^{\text {th }} 9^{\text {th }} 10^{\text {th }} 11^{\text {th }} 12^{\text {th }} \quad 13^{\text {th }} 14^{\text {tb }}
$$

4. What is the zip code of your home address?

5. Who lives in your family home? (Please fill in all that apply.)
a) Mother: yes $\square$
no $\square$
b) Father:
yes $\square$
no $\square$
unknown $\square$
c) Brothers: yes 0
no $\square$
unknown $\square$

If yes,

1. How many older brothers live in your home? (Please circle correct answer.)

$$
\begin{array}{lllllllllll}
1 & 2 & 3 & 4 & 5 & 6 & 7 & 8 & 9 & 10 & \text { unknown }
\end{array}
$$

2. How many younger brothers live in your home? (Please circle correct answer.)

$$
\begin{array}{lllllllllll}
\text { I } & 2 & 3 & 4 & 5 & 6 & 7 & 8 & 9 & 10 & \text { unknown }
\end{array}
$$

d) Sisters: yes $\square$ no $\square$ unknown $\square$

If yes,

1. How many older sisters live in your home? (Please circle correct answer.)

$\begin{array}{llllllllllll}1 & 2 & 3 & 4 & 5 & 6 & 7 & 8 & 9 & 10 & \text { unknown }\end{array}$

2. How many younger sisters live in your home? (Please circle correct answer.)

$$
\begin{array}{lllllllllll}
1 & 2 & 3 & 4 & 5 & 6 & 7 & 8 & 9 & 10 & \text { unknown }
\end{array}
$$

c) Other relatives: yes $\square^{\cdot}$ no $\square$ unknown $\square$ How many? (Please circle correct answer.)

$$
\begin{array}{lllllllllll}
1 & 2 & 3 & 4 & 5 & 6 & 7 & 8 & 9 & 10 & \text { unknown }
\end{array}
$$

f) Non-relatives: yes $\square$ no $\square$ unknown $\square$ How many? (Please circle correct answer.) 


\section{Part A: Demographic Questions (NIY) continued}

Directions: Please indicate the correct answer to the following questions by either circling the answer or filling in the box next to the answer of your choice.

6. Who in your home attends school? (Please fill in all that apply)
a) Mother: yes $\square$
no. 0
b) Father: yes $\square$
no $\square$
no 0
c) Brothers: yes $\square$
no $\square$
unknown $\square$
unknown $\square$
unknown $\square$.
d) Sisters: yes $\square$
unknown $\square$.

7. Who is employed in the household? (Please fill in all that apply)
a) Mother:
yes $\square$
no $\square$
unknown $\square$
b) Father:
yes $\square$
no $\square$
unknown $\square$
c) Brothers:
yes
no $\square$
no $\square$
unknown $\square$
d) Sisters:
yes
no $\square$
unknown
e) Other relatives:
yes
no $\square$
unknown $\square$
f) Non-relatives:
yes
unknown $\square$

8. Does your family own a car?

Yes $\square$ No $\square$ : unknown $\square$

9. Does your family own their home?
Yes $\square$
No $\square$
unknown $\square$ 


\section{APPENDIX B}

\section{USE OF VIOLENCE SCALE}

Centers for Disease Control. (1999). 1999 Youth risk behavior survey. CDC Chronic Disease Adolescent Health. [On-line], xx. Available:

http://www.cdc.gov/nccdphp/dash/yrbs/ survey99.htm

DuRant, R. H., Cadenhead, C., Pendergrast, R. A., Slavens, G., \& Linden, C. W. (1994). Factors associated with the use of violence among urban black adolescents. American Journal of Public Health, 84(4), 612.

Huizinga, D., Esbensen, F., \& Weiher A. (1991). Are there multiple paths to delinquency. Journal of Criminal Law and Criminology, 82, 83-119 
The Survey of African American Male Youth Experience and Behavior - Instruments

Joy Leary: Ph.D. Candidate

\section{Part G. UVS Scale (NIY)}

Please indicate how often you have been involved in the following events, please circle the number that best describes how often you have been in engaged in these events.

$$
0=\text { Never } \quad 1=\text { Sometimes } \quad 2=\text { Often } 3=\text { Very Often }
$$

EXAMPLE: If you have often slapped your girlfriend you would circle $\underline{2}$ below:

Ever hit or slap your girlfriend on purpose

$0 \quad 1 \quad 2$

23

Item \#

110. Attacked someone you lived with out of anger

$\begin{array}{llll}0 & 1 & 2 & 3\end{array}$

11. Involved in a physical fight in the past months

$\begin{array}{llll}0 & 1 & 2 & 3\end{array}$

112. In the previous 12 months, received an injury during a physical fight requiring medical care

113. Been involved in a gang fight

$\begin{array}{llll}0 & 1 & 2 & 3 \\ 0 & 1 & 2 & 3 \\ 0 & 1 & 2 & 3 \\ 0 & 1 & 2 & 3\end{array}$

115. Ever carried a hidden weapon

116. Attacked someone with a weapon with the idea of seriously hurting or killing them

$\begin{array}{llll}0 & 1 & 2 & 3\end{array}$




\section{APPENDIX C}

\section{SURVEY OF EXPOSURE TO COMMUNITY VIOLENCE}

Richters, J. E. (1990). Screening survey of exposure to community violence: Self report version. (Available from National Institute of Mental Health, 5600 Fishers Lane, Room 18C-17, Rockville, MD 20857). 
The Survey of African American Male Youth Experience and Behavior - Instruments

\section{Part E. SECVW Scale (NIY)}

Read each statement and circle the number that best describes how often you have witnessed the following. Please do not circle more than one answer per question.

$$
0=\text { Never } \quad 1=\text { Sometimes } \quad 3=\text { Often } \quad 3 \text { =Very Often }
$$

EXAMPLE: If you have never witnessed someone being attacked by a group you would circle $\underline{\mathbf{0}}$ below:

Have you ever witnessed someone being attacked by a group of people?

$\begin{array}{llll}0 & 1 & 2 & 3\end{array}$

Item \#

87. Have you ever witnessed anyone being chased when it wasn't just for fun?

$\begin{array}{llll}0 & 1 & 2 & 3\end{array}$

88. Have you ever witnessed someone being hit by a member of your family?

0 112

89. Have you ever witnessed someone being hit by non-family members?

$\begin{array}{llll}0 & 1 & 2 & 3\end{array}$

90. Have you ever witnessed someone being beaten or mugged?

$\begin{array}{llll}0 & 1 & 2 & 3\end{array}$

91. Have you ever witnessed someone being sexually assaulted?

$\begin{array}{llll}0 & 1 & 2 & 3\end{array}$

92. Have you ever witnessed someone being attacked with a knife?

$\begin{array}{llll}0 & 1 & 2 & 3\end{array}$

93. Have you ever witnessed someone being seriously wounded after a serious incident of violence?

$\begin{array}{llll}0 & 1 & 2 & 3\end{array}$

94. Have you ever witnessed someone being shot at?

95. Have you ever witnessed a serious accident?

$\begin{array}{llll}0 & 1 & 2 & 3 \\ 0 & 1 & 2 & 3 \\ 0 & 1 & 2 & 3 \\ 0 & 1 & 2 & 3\end{array}$

97. Have you ever witnessed a murder? 
The Survey of A frican American Male Youth Experience and Behavior - Instruments

Joy Leary; Ph.D. Candidate

Part F. SECVV Scale (NIY)

Read each statement and circle the number that best describes how often you have had this experience with it. Please do not circle more than one answer per question.

$$
0=\text { Never } \quad 1=\text { Sometimes } \quad 2=\text { Often } \quad 3=\text { Very Often }
$$

EXAMPLE: If you have sometimes been attacked by a group you would circle $\underline{1}$ below:

Have you ever been attacked by a group of people?

$\begin{array}{llll}0 & 1 & 2 & 3\end{array}$

Item \#

98. Have you ever been chased when it wasn't just for fun?

99. Have you ever been hit by family members?

100. Have you ever been hit by non-family members?

$\begin{array}{llll}0 & 1 & 2 & 3\end{array}$

101. Have you ever been beaten or mugged?

$\begin{array}{llll}0 & 1 & 2 & 3\end{array}$

102. Have you ever been sexually assaulted?

103. Have you ever been attacked with a knife?

$\begin{array}{llll}0 & 1 & 2 & 3\end{array}$

104. Have you ever been seriously wounded after an incidence of violence?

$\begin{array}{llll}0 & 1 & 2 & 3\end{array}$

105. Have you ever been shot or shot at by someone
106. Has your home ever been broken into when you
were at home?

107. Have you ever shot or shot at someone else?

$\begin{array}{llll}0 & 1 & 2 & 3 \\ 0 & 1 & 2 & 3\end{array}$

\section{(Please fill in the box of the correct answer .)}

108. Do you own a gun? yes $\square$ no $\square$ unknown $\square$

109. Is there a gun in your household? yes $\square$ no unknown $\square$ 


\section{APPENDIX D}

\section{URBAN HASSLES SCALE}

Miller, D. B. (1999). Urban hassles scale. Unpublished manuscript, Case Western Reserve University, Mandel School of Applied Social Sciences, Cleveland. 
The Survey of African American Male Youth Experience and Behavior - Instruments

Joy Leary; Ph.D. Candidate

\section{Part B. UHS-NIY Scale}

How often do the following happen to you? Thinking back over the last 12 months, please indicate how often these events have happened to you. Please circle the number that best describes how often an event happened to you. Please do not circle more than one answer per question.

$$
\text { 0=Never } \quad 1 \text { =Sometimes } \quad 2=\text { Often } \quad 3=\text { Very Often }
$$

EXAMPLE: If you felt like you were being followed in department stores by sales people Sometimes you would circle number I below:

Being followed in department stores by sales people

$\begin{array}{llll}0 & 1 & 2 & 3\end{array}$

How often do the following happen to you?

Item \#

10. Asked for money bydrug addicts

11. Take different routes home in order to keep safe $\quad \begin{array}{llllll}0 & 1 & 2 & 3\end{array}$

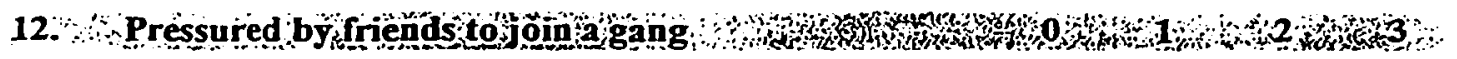

$\begin{array}{lllllll}\text { 13. Made fun of because of grades } & 0 & 1 & 2 & 3\end{array}$

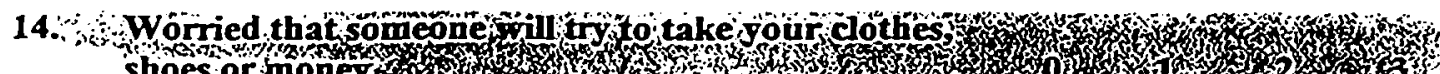
shoes or money

$\begin{array}{lllllll}\text { 15. Pressured to carry weapon for protection } & 0 & 1 & 2 & 3\end{array}$

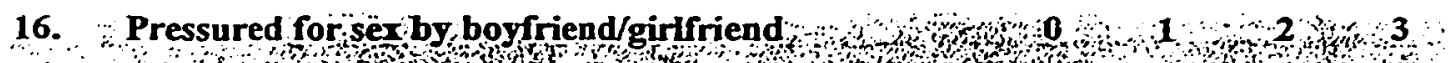

17. 1.0 .

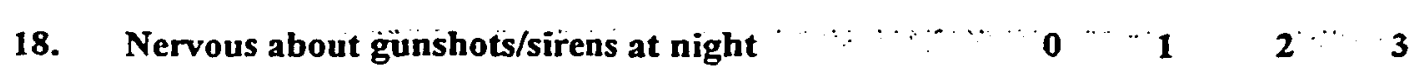

19. Worrying about safety of friends and family members

$\begin{array}{llll}0 & 1 & 2 & 3\end{array}$

20. Keeping your fear about safety secret from your friends

21. Offered sex by drug addicts for moncy $\quad \begin{array}{llllll}0 & 0 & 2 & 2 & 3\end{array}$ 
The Survey of African American Male Youth Experience and Behavior - Instruments

Joy Leary: Ph.D. Candidate

\section{Part B. UHS-IY Scale}

How often do the following happen to you? Thinking back to before you were incarcerated, please indicate how often these events have happened to you. Please circle the number that best describes how often an event happened to you. Please do not circle more than one answer per question.

$$
0=\text { Never } \quad 1=\text { Sometimes } \quad 2=\text { Often } \quad 3=\text { Very Often }
$$

EXAMPLE: If you felt like you were being followed in department stores by sales people Sometimes you would circle number I below:

Being followed in department stores by sales people

$\begin{array}{llll}0 & 1 & 2 & 3\end{array}$

How often do the following happen to you?

Item \#

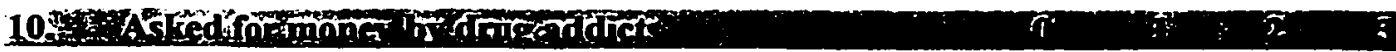

11. Take different routes home in order to keep safe $\quad \begin{array}{lllll}0 & 1 & 2 & 3\end{array}$ 123.

i

13. Made fun of because of grades

$\begin{array}{llll}0 & 1 & 2 & 3\end{array}$

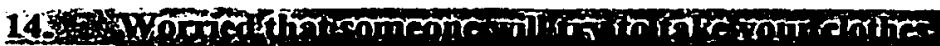
Sho-tontmath

15. Pressured to carry weapon for protection
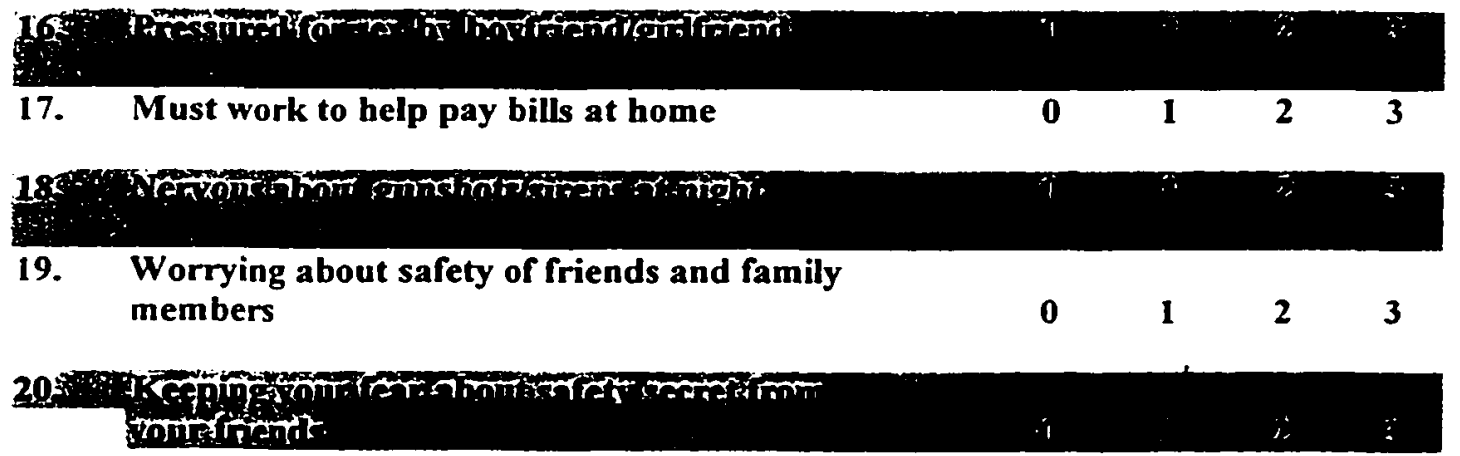

21. Offered sex by drug addicts for money

$\begin{array}{llll}0 & 1 & 2 & 3\end{array}$




\section{APPENDIX E}

\section{SCALE OF RACIAL SOCIALIZATION- ADOLESCENT VERSION}

Stevenson, H. C. (1994a). Racial socialization in African American families: The art of balancing intolerance and survival. The Family Journal: Counseling Therapy for Couples and Families, 2(3), 190-198. 
The Survey of African American Male Youth Experience and Behavior - Instruments

Joy Leary; Ph.D. Candidate

\section{Part D. SORS-A - Adolescent Version (NIY)}

Read each statement and circle the number that best describes how much you agree/disagree with it. Please do not circle more than one answer per question.

$0=$ Disagree a lot 1=Disagree a little 2=Not sure $3=$ Agree a little 4=Agree a lot

EXAMPLE: If you are Not sure if the images of Black people on television are usually positive you would circle number 2 below:

Images of Black people on television are usually positive

$\begin{array}{lllll}0 & 1 & 2 & 3 & 4\end{array}$

Item \#

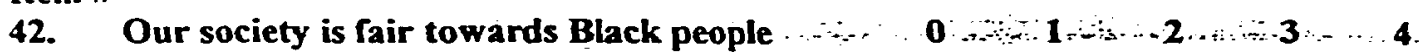

43. Grandparents help parents to make decisions $\quad \begin{array}{llllll}0 & 1 & 2 & 3 & 4\end{array}$

44. Black children will feel good about being
Black in a school with mostly White children. 0.2

45. It is important for families to go to church or $\begin{array}{lllllll}\text { Mosque where spiritual growth can happen } & 0 & 1 & 2 & 3 & 4\end{array}$

46. Families should talkabout Black slavery 40.040

47. Relatives can help Black parents raise their children

$\begin{array}{lllll}0 & 1 & 2 & 3 & 4\end{array}$

48. Religion is an important part of a person's life

$\begin{array}{llllll} & 0 & 1 & 2 & 3 & 4\end{array}$

49. Racism and discrimination are the hardest things a Black child has to face

$\begin{array}{lllll}0 & 1 & 2 & 3 & 4\end{array}$

50. Having large families can help many Black families survive life's struggles

51. Families of Black children should teach them to be proud to be Black

$\begin{array}{lllll}0 & 1 & 2 & 3 & 4\end{array}$

52 Children should be taught that all races are equal

$\begin{array}{lllll}0 & 1 & 2 & 3 & 4\end{array}$
Children who have good times with their relatives become better people

$\begin{array}{lllll}0 & 1 & 2 & 3 & 4\end{array}$


The Survey of African American Male Youth Experience and Behavior - Instruments

Joy Leary: Ph.D. Candidate

\section{Part D. SORS-A - Adolescent Version (NIY)}

Read each statement and circle the number that best describes how much you

agree/disagree with it. Please do not circle more than one answer per question.

$0=$ Disagree a lot $\quad 1$ =Disagree a little $2=$ Not sure $\quad 3=$ Agree a little $\quad 4=$ Agree a lot

54. A belief in God can help a person deal with tough life struggles

$\begin{array}{llllll}0 & 1 & 2 & 3 & 4\end{array}$

55. A mostly Black school will help Black children learn more than a mostly White school

$\begin{array}{lllll}0 & 1 & 2 & 3 & 4\end{array}$

56. Spending good time with relatives is just as important for parents as it is for their children

57. Black parents should teach their children about racism

$\begin{array}{lllll}0 & 1 & 2 & 3 & 4\end{array}$

58. Black parents should talk about their roots to African culture to their children

$\begin{array}{lllll}0 & 1 & 2 & 3 & 4\end{array}$

59. Relatives can teach children things that parents may not know

$\begin{array}{lllll}0 & 1 & 2 & 3 & 4\end{array}$

60. Families who talk about racism to their children will lead them to doubt themselves

$\begin{array}{lllll}0 & 1 & 2 & 3 & 4\end{array}$

61. Schools should be required to teach all children about Black history

$\begin{array}{lllll}0 & 1 & 2 & 3 & 4\end{array}$

62. Depending on religion and God can help a person make good life decisions

$\begin{array}{lllll}0 & 1 & 2 & 3 & 4\end{array}$

63. Families who talk openly about religion or God are helping their children grow

$\begin{array}{lllll}0 & 1 & 2 & 3 & 4\end{array}$

64. Teachers should make it so Black children can see signs of Black culture in the classroom

$\begin{array}{lllll}0 & 1 & 2 & 3 & 4\end{array}$

65. Only people who are blood related to you should be called your family

$\begin{array}{lllll}0 & 1 & 2 & 3 & 4\end{array}$

66. Getting a good education is still the best way for a Black child to survive racism

$\begin{array}{lllll}0 & 1 & 2 & 3 & 4\end{array}$


The Survey of African American Male Youth Experience and Behavior - Instruments

\section{Part D. SORS-A - Adolescent Version (NIY) continued}

Read each statement and circle the number that best describes how much you agree/disagree with it. Please do not circle more than one answer per question.

$0=$ Disagree a lot $1=$ Disagree a little $2=$ Not sure $3=$ Agree a little $4=$ Agree a lot

67 Don't forget who your people are because you may need them some day

$\begin{array}{lllll}0 & 1 & 2 & 3 & 4\end{array}$

68. When children are younger than 5 racism does not bother them

$\begin{array}{lllll}0 & 1 & 2 & 3 & 4\end{array}$

69. Spiritual battles that people fight are more important than the physical battles

$\begin{array}{lllll}0 & 1 & 2 & 3 & 4\end{array}$

70. Teaching children about Black history will help them to survive $a$ hostile world

$\begin{array}{lllll}0 & 1 & 2 & 3 & 4\end{array}$

71. Train up a child in the way he should go and and he will not turn away from it

$\begin{array}{lllll}0 & 1 & 2 & 3 & 4\end{array}$

72. A Black child has to work twice as hard in order to get ahead in this world

$\begin{array}{lllll}0 & 1 & 2 & 3 & 4\end{array}$

73. Watching parents struggle to find work can make many Black children wonder if it is worth it to succeed in the world

$\begin{array}{lllll}0 & 1 & 2 & 3 & 4 \\ 0 & 1 & 2 & 3 & 4\end{array}$

75. Black children at a mostly Black school will feel better about themselves than those who go to a mostly White school

$\begin{array}{lllll}0 & 1 & 2 & 3 & 4\end{array}$

76. Black parents need to teach their children how to live in two worlds; one Black and one White

$\begin{array}{lllll}0 & 1 & 2^{\prime} & 3 & 4\end{array}$

77. Light skinned Black persons often think they are better than darker skinned Blacks

$\begin{array}{lllll}0 & 1 & 2 & 3 & 4\end{array}$

78. Whites do not have more opportunities than Blacks

$\begin{array}{lllll}0 & 1 & 2 & 3 & 4\end{array}$


The Survey of African American Male Youth Experience and Behavior - Instruments

Joy Leary: Ph.D. Candidate

\section{Part D. SORS-A - Adolescent Version (NIY)}

Read each statement and circle the number that best describes how much you

agree/disagree with it. Please do not circle more than one answer per question.

$0=$ Disagree a lot I=Disagree a little $2=$ Not sure $3=$ Agree a little $4=$ Agree a lot

79. A Black child or teenager will not be harassed simply because she or he is black

$\begin{array}{lllll}0 & 1 & 2 & 3 & 4\end{array}$

80. More job opportunities would be open to African

Americans if people were not racist

81 Black children should be taught early that God can protect them from racial hatred

$\begin{array}{lllll}0 & 1 & 2 & 3 & 4\end{array}$

82. Whites do not think of Black people as lazy or aggressive today like they used to believe $\mathbf{3 0}$ or more years ago

$\begin{array}{lllll}0 & 1 & 2 & 3 & 4\end{array}$

83. Black parents should not teach their children to speak their mind because they could be attacked by others in society

$\begin{array}{lllll}0 & 1 & 2 & 3 & 4\end{array}$

84. If Black parents teach their children that Blacks don't always have the same opportunities as Whites, they may help them to survive racism and be successful

0

1

23

4

85. Black children don't have to know about Africa in order to survive life in America

$\begin{array}{lllll}0 & 1 & 2 & 3 & 4\end{array}$

86. My family taught me very little about racism in America

0

1

2

34




\section{APPENDIX F \\ AFRICAN AMERICAN RESPECT SCALE-MALE ADOLESCENT VERSION}

Leary, J. D. (1999, January). African American Respect Scale-Male Adolescent Version. Unpublished scale. Portland, OR: Portland State University. 
The Survey of African American Male Youth Experience and Behavior - Instruments Joy Leary; Ph.D. Candidate

Part C.: AARS Scale for Male Adolescents (NIY)

Directions: Here is a set of statements that tell what a person thinks about respect. Read each statement and decide whether or not it describes what you think about respect. Please do not circle more than one answer per question. Remember. There are no right or wrong answers.

$\begin{array}{llll}0=\text { strongly disagree } & 1=\text { disagree } & 2=\text { agree } & 3=\text { strongly agree }\end{array}$

EXAMPLE: If you strongly agree that fights can start when people raise their voices you would circle number 3 below:

Fights can stan when people raise their voices

Item \#

22. I admire my family $=$ s

23. People treat me well because they are afraid of me. $\quad \begin{array}{lllll}0 & 1 & 2 & 3\end{array}$

24. It is dificult to get appreciation as a black iman $-7 \cdot \cdots$

25. The police trust and appreciate me. $\quad 30 \begin{array}{llll}1 & 2 & 3\end{array}$

26. I listen to and appreciate the guidance my parents give

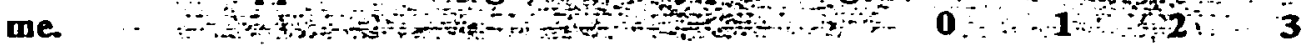

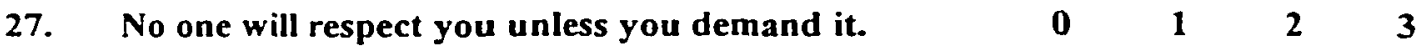

28. African Americans are highly regarded in America. 0.30 A a

29. I am valued and appreciated by my teachers. $\quad \begin{array}{llllll}0 & 1 & 2 & 3\end{array}$

30. I am proud of my family's achievements. $\because \cdots \quad \begin{array}{lllll} & 0 & 1 & 2 & 3\end{array}$

31. A girl appreciates a young man that takes control. $\quad 3 \quad 0 \quad 1 \quad 2 \quad 3$

32. People will admire me if $\mathbf{I}$ have expensive things. $\quad 0 \quad 0 \quad 1 \quad \ldots \quad 2, \quad 3$

33. Sales people are happy to assist me in department stores.

0 1, 2 3

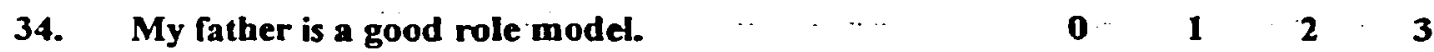

35. I may hurt someone if they try to embarrass me

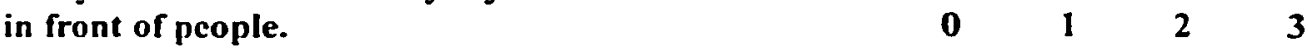

36. If someone curses at a member of my family: I might hurt them Q $\quad 1 \quad 2 \quad 3$ 


\section{Part C.: AARS Scale for Male Adolescents (NIY) continued}

Directions: Here is a set of statements that tell what a person thinks about respect. Read each statement and decide whether or not it describes what you think about respect. Please do not circle more than one answer per question. Remember: There are no right or wrong answers.

$0=$ strongly disagree $\quad 1=$ disagree $\quad 2=$ agree $\quad 3=$ strongly agree

Item \#

37. I have a good chance of getting good jobs that I qualify for.

$\begin{array}{llll}0 & 1 & 2 & 3\end{array}$

38. My family admires and appreciates me. $\ldots \quad \cdots \quad-\quad 0 \quad 1+2,-3$.

39. Someone can offend me by the way they look at me. $\begin{array}{lllll}0 & 1 & 2 & 3\end{array}$

40. You can get respect if you are in a gang. $\quad 0 \quad 0 \quad 1 \quad 2 \quad 3$

41. When I am in a bank or other places of business people are helpful and pleasant towards me.

$\begin{array}{llll}0 & 1 & 2 & 3\end{array}$


APPENDIX G

AFRICAN AMERICAN RESPECT SCALEOPEN-ENDED QUESTIONS 
The Survey of African American Male Youth Experience and Behavior - Instruments Joy Leary, Ph.D. Candidate

\section{Part H. OEQ Questions (NIY)}

Please write a brief answer to the following questions.

Item \#117.

If you and your friends have felt disrespected at some time in your life, why do you think it happened?

Item \# 118.

Why do you think people like you are disrespected? 